\title{
Article \\ Global Sliding-Mode Control with Fractional-Order Terms for the Robust Optimal Operation of a Hybrid Renewable Microgrid with Battery Energy Storage
}

\author{
Muhammad Maaruf 1,2,3 (D) and Muhammad Khalid 2,3,4,*(D) \\ 1 Systems Engineering Department, King Fahd University of Petroleum \& Minerals, \\ Dhahran 31261, Saudi Arabia; g201705070@kfupm.edu.sa \\ 2 Center for Renewable Energy and Power Systems, King Fahd University of Petroleum \& Minerals, \\ Dhahran 31261, Saudi Arabia \\ 3 K.A.CARE Energy Research \& Innovation Center, King Fahd University of Petroleum \& Minerals, \\ Dhahran 31261, Saudi Arabia \\ 4 Electrical Engineering Department, King Fahd University of Petroleum \& Minerals, \\ Dhahran 31261, Saudi Arabia \\ * Correspondence: mkhalid@kfupm.edu.sa
}

Citation: Maaruf, M.; Khalid, M. Global Sliding-Mode Control with Fractional-Order Terms for the Robust Optimal Operation of a Hybrid Renewable Microgrid with Battery Energy Storage. Electronics 2022, 11, 88. https://doi.org/ 10.3390/electronics11010088

Academic Editor: Jahangir Hossain

Received: 18 November 2021

Accepted: 21 December 2021

Published: 28 December 2021

Publisher's Note: MDPI stays neutral with regard to jurisdictional claims in published maps and institutional affiliations.

Copyright: (C) 2021 by the authors. Licensee MDPI, Basel, Switzerland. This article is an open access article distributed under the terms and conditions of the Creative Commons Attribution (CC BY) license (https:// creativecommons.org/licenses/by/ $4.0 /)$.

\begin{abstract}
The efficiency of hybrid microgrid systems is drastically affected by the number of power electronics converters interfacing with its components. Integrating distributed energy sources with microgrids with the optimal number of converters is crucial to minimizing the switching losses and power conversion stages, thereby improving the efficiency of the systems. This paper considers an efficient and economical configuration for a wind/solar photovoltaic (PV) system integrated with a battery energy storage system (BES). The PV system is connected directly to the DC-link, thus lowering the losses and cost by eliminating the PV boost converter. In the literature, only a few publications have investigated this effective microgrid configuration. In addition, none of the publications have developed a nonlinear control approach for the microgrid configuration. Due to the greater flexibility of fractional calculus in speeding up the system response and improving the robustness, this article proposes a global sliding-mode control method with fractional-order terms (GSMCFO) to enhance the transient, steady-state, and robust operation of the hybrid microgrid. This controller provides the maximum power point tracking (MPPT) of both the solar PV and wind power generators, regulates the DC-link voltage, ensures proper power transfer to the grid, and maintains the power balance. In addition, the GSMCFO guarantees the global stability of the hybrid microgrid. Furthermore, considering the simplicity, robustness, few control variables, and fast convergence rate of the differential evolution (DE) optimization method, it is utilized to optimize the performance of the GSMCFO. The proposed hybrid microgrid configuration under the action of the GSMCFO was simulated in MATLAB/SIMULINK. Various scenarios were investigated to illustrate the feasibility of the proposed scheme. The simulation results show that the GSMCFO can achieve superior dynamic performances than the proportional-integral (PI) controller with zero overshoot, a shorter settling time, and stronger robustness, thus improving the power balance of the hybrid microgrid.
\end{abstract}

Keywords: solar PV system; wind power; global sliding-mode control; fractional-order operation; battery energy storage system

\section{Introduction}

Over the past few decades, the energy consumption in urban areas has increased due to industrialization, improvement in the quality of life, and urbanization [1]. This energy is largely from fossil fuels, which have harmful effects, such as climate change, the green house effect, environmental pollution, and global warming [2]. At the same time, inordinate utilization depletes the reserves of this resource. Therefore, the use of fossil fuels for power generation is discouraged in order to lessen the green house effect and climate change. 
Renewable energy sources such as wind, solar, hydro, geothermal, etc., are becoming popular as they are inexpensive, efficient, and reliable [3]. Investments in renewable energy have kept increasing despite the world economic crisis of 2008, which ravaged the world economy. Many companies and private organizations are moving toward these energy sources [4]. The advances in power electronics technology has led to the increase in energy conversion efficiencies and the continuing fall in the costs of PV systems and wind turbines [5]. The global capacities of installed solar and wind power were $586 \mathrm{GW}$ and $623 \mathrm{GW}$, respectively, at the beginning of 2020 [6]. However, their outputs are highly intermittent, that is they depend on the ambient conditions. PV and wind renewable energy sources have complementary properties [7], that is, during the day, the output from the PV system is high, whereas wind turbine power generation is low. On the other hand, during the night, solar irradiance is unavailable; thus, the PV system is not generating power, while the output power of the wind turbine is high. The PV system and the wind turbines can be tied to a common DC bus to obtain a hybrid microgrid. The hybrid microgrid tackles the insufficiency and uncertainty of the energy sources [8]. Furthermore, it is essential to harness the maximum power from the PV system and the wind turbine under any operating condition. The MPPT algorithm is vital for optimal operation and harnessing peak power [9]. In [10], an ant colony optimization algorithm was used to optimize the performance of the MPPT for an islanded PV/Wind microgrid. In [11], the artificial bee colony optimization algorithm was implemented for the MPPT operation of a hybrid PV/wind power generation plant. In [12], a perturb and observe (P\&O) algorithm was used to obtain the MPPT of solar PV. In [13], an advanced multi-sector P\&O-based MPPT scheme was developed for a grid-connected wind turbine. A fuzzy logic controller optimized with ACO was used to realize the MPPT operation of an islanded PV/wind system [14]. In [15], a sensorless MPPT approach was developed for a hybrid microgrid comprising a doubly-fed induction generator (DFIG) and PV system. In [16], a fuzzy logic control optimized with particle swamp optimization was presented for the MPPT of an on-grid PV/wind system. In [17], an intelligent control technique coupled with the MPPT was developed for a PV/wind system connected to the grid. A fuzzy PI technique was proposed in [18] for enhancing the MPPT performance of a PV/wind system.

The active power generated by a PV/wind system occasionally exceeds the demand, and curtailment of the active power is inevitable to effectively balance the microgrid power [19]. However, power curtailment contradicts the economic and environmental goals of renewable integration. In the situation where the demand is higher than the generated power, load shedding is employed to maintain the balance [20]. The emergence of high-capacity BESs has proven promising in storing energy when there is excess available and to provide it when required [21]. The reliability, safety, and efficient operation of the BES can be ensured by monitoring the state-of-charge (SOC) of the BES [22]. In the literature, different BES models such as the electrical model [23] and electrochemical model [24] have been used to investigate the behavior of the BES and its SOC. Several methods have been proposed for estimating the SOC such as ensemble-based state estimator [24], super twisting observer [25], and Frisch-scheme-based bias compensating recursive least squares (FBCRLS) [26]. In [27], an SOC control of BES was developed to prevent the degradation of the BES. In [28], an optimal distributed control of a BES connected to the microgrid was investigated to improve the life of the BES. In [29], a power quality control of an islanded microgrid with admissible BES constraints was studied. A data-driven control method was proposed in [30] to improve the performance of the grid-supporting BES. In [31], a coordinated control of the microgrid with the BES was presented to regulate the grid voltage. The authors in [32] incorporated a BES into a PV/wind microgrid to smooth the power generated. In [33], the energy management and control of a PV/wind/BES microgrid were presented. In [34], a model-predictive-control-based power management system was developed for a hybrid microgrid. In [35], a distributed BES control was designed for a hybrid microgrid with unbalanced generation. 
The aforesaid papers did not consider a cost-effective, efficient, and optimal configuration of the hybrid microgrid. An efficient and cost-effective hybrid microgrid configuration can be obtained by minimizing the number of power electronics components and thus reducing the power conversion stages. To the best of our knowledge, only a handful of literature works have considered this optimal microgrid configuration. In [36], the least mean mixed-norm (LMMN) control method was proposed for the new microgrid topology consisting of a wind-turbine-driven permanent magnet synchronous generator (PMSG) and solar PV. The authors in [37] proposed the power management and control of a wind/PV system including a BES with an optimal number of power converters. In [38], a simple and efficient microgrid topology was developed for a grid-connected wind/PV generation system. In these papers, the PV array was connected directly to the DC-link without the usual PV boost converter, giving high efficiency due to an optimal number of components, which reduced the intermediate stage losses and improved PV power usage. Moreover, the DC-link voltage was controlled to attain the MPPT of the solar PV system. However, these papers used linear control methods. These controllers will give unsatisfactory transient and steady-state performances in the presence of parametric uncertainties or a sudden change in the operating point due to fluctuating nature of renewable energy sources and load variations. To improve the response time of the system under varying parameters, a nonlinear control method can be investigated. However, to the best of our knowledge, no study has presented the nonlinear control for a hybrid microgrid with the optimal number of converters.

In this study, the problem of developing a nonlinear control method for a hybrid microgrid considering an optimal and efficient hybrid microgrid configuration is investigated. The hybrid microgrid in this study consists of a wind-turbine-driven PMSG, solar PV system, BES, load, and utility grid. A GSMCFO is proposed to ensure robustness and proper transient and steady-state performances and guarantee the global stability of the hybrid microgrid under any operating condition. The main contributions of this article are given as follows:

1. A novel fractional-order controller (GSMCFO) was designed to control the hybrid microgrid. The important attribute of this controller is the disturbance attenuation. The effect of the disturbances and uncertainties were taken into account in designing the GSMCFO;

2. The GSMCFO achieves the MPPT of both solar PV and a wind-turbine-based PMSG, regulation of the DC-link voltage, and power balance by controlling the battery current with excellent transient and steady-state performances;

3. The GSMCFO guarantees the global stabilization of the hybrid microgrid despite the variation of renewable power sources and the load;

4. A performance comparison is presented to validate the accuracy, superiority, and robustness of the proposed GSMCFO with a proportional-integral (PI) controller.

The rest of the paper is arranged as follows: The preliminaries are provided in Section 2. The mathematical model of the hybrid microgrid is derived in Section 3. The GSMCFO is designed in Section 4. The simulation results are given in Section 5. In Section 6, the conclusions are presented.

\section{Preliminaries}

This section presents the definitions and properties of the fractional-order calculus, lemmas, and assumptions.

\section{Brief Overview of Fractional Derivatives}

There are various definitions of fractional derivatives in the literature, but the most popular ones are Caputo's, Riemann-Liouville's, and Grunwald-Letnikov's derivative definitions [39]. 
Definition 1. The Caputo fractional derivative of a continuous function $\phi(t)$ is described by:

$$
{ }_{t_{0}}^{C} \mathcal{D}_{t}^{\mu} \phi(\tau)=\frac{1}{\Gamma(m-\mu)} \int_{t_{0}}^{t} \frac{\phi(\tau)}{(t-\tau)^{\mu-n+1}} d \tau
$$

where $m-1<\mu \leq m \in \mathbb{Z}^{+}, \phi^{m}(\tau)$ stands for the $n$-th time derivative of $\phi(\tau)$ and $\Gamma(m-\mu)$ is a Gamma function.

Definition 2. The Riemann-Liouville fractional derivative of a continuous function $\phi(t)$ is described by:

$$
{ }_{t_{0}}^{R} \mathcal{D}_{t}^{\mu} \phi(t)=\frac{1}{\Gamma(m-\mu)} \frac{d^{m}}{d t^{m}} \int_{t_{0}}^{t} \frac{\phi^{m}(\tau)}{(t-\tau)^{\mu-n+1}} d \tau
$$

Definition 3. The Riemann-Liouville fractional integration of a continuous function $\phi(t)$ is described by:

$$
{ }_{t_{0}}^{R} \mathcal{I}_{t}^{\mu} \phi(t)=\frac{1}{\Gamma(\mu)} \int_{t_{0}}^{t} \frac{\phi^{m}(\tau)}{(t-\tau)^{1-\mu}} d \tau
$$

Property 1 ([40]). If $0<\mu<1$, then:

$$
{ }_{t_{0}}^{C} \mathcal{D}_{t}^{\mu}\left({ }_{t_{0}}^{C} \mathcal{I}_{t}^{\mu} \phi(t)\right)=\phi(t)
$$

Property 2 ([41]). If $0<\mu<1$, then:

$$
{ }_{t_{0}}^{C} \mathcal{D}_{t}^{\mu-1}\left({ }_{t_{0}}^{C} \mathcal{I}_{t}^{\mu} \phi(t)\right)=\dot{\phi}(t)
$$

The fractional-order integration or differentiation calculus are linear operations, which is similar to the integer-order calculus.

Property 3 ([41]). The fractional derivative or integration is a linear operation:

$$
\mathcal{D}_{t}^{\mu}\left(\phi_{1}(t)+\phi_{2}(t)\right)=\mathcal{D}_{t}^{\mu} \phi_{1}(t)+\mathcal{D}_{t}^{\mu} \phi_{2}(t)
$$

Lemma 1. If there exists a smooth and positive-definite function L satisfying the following inequality:

$$
\dot{L} \leq-\varrho(2 L)^{\frac{\alpha+1}{2}}-\gamma(2 L)
$$

where $\varrho, \gamma$, and $\alpha$ are positive constants, then the system $\dot{\chi}(t)=f(\chi, t)$ is globally finite time stable. The settling time $T_{r}$ is defined by:

$$
T_{r}=\frac{1}{\gamma_{i}(1-\alpha)} \ln \left(1+\frac{\gamma_{i}}{\varrho_{i}}\left\|\zeta_{i}(0)\right\|_{2}^{1-\alpha}\right)
$$

Assumption 1. The lumped external disturbances and parametric perturbations in the hybrid microgrid $\left(H_{i} i=1,2, \ldots, n\right)$, with $n$ being the number of outputs, are bounded.

$$
\left\|H_{i}\right\| \leq{ }^{R} \mathcal{I}_{t}^{1-\mu} \delta_{i} \text {, and }\left\|^{R} \mathcal{D}_{t}^{1-\mu} H_{i}\right\| \leq \delta_{i}
$$

where $\delta_{i}$ is a positive function.

\section{Modeling of the Hybrid Microgrid}

The schematic configuration of the hybrid microgrid system is shown in Figure 1. It comprises a PV array, PMSG driven by a wind turbine, BES, rotor-side converter (RSC), grid-side converter (GSC), and bidirectional DC-DC buck/boost converter. The PV array is linked directly to the DC-link. A diode is connected in series with the PV array to avoid 
destruction as a result of the reverse flow of current. The battery storage system is tied to the DC-link through the DC-DC buck/boost converter.

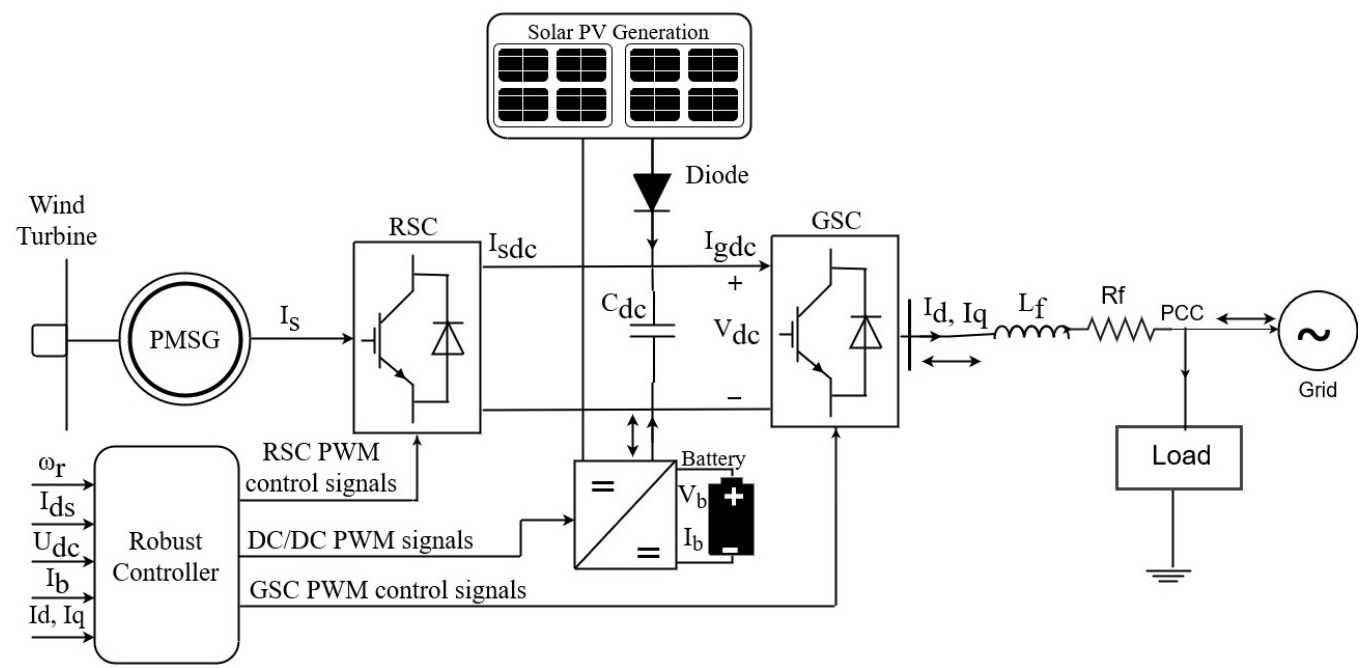

Figure 1. PV/wind/battery microgrid system.

\subsection{Modeling of the Wind Turbine}

The mechanical power captured by the wind turbine from the wind is given by [42]:

$$
\begin{gathered}
P_{w}=\frac{1}{2} \rho \pi R^{2} C_{p}(\lambda, \beta) V_{w}^{3} \\
C_{p}(\lambda, \beta)=0.5176\left(\frac{116}{\lambda_{i}}-0.4 \beta-5\right) e^{\frac{-21}{\lambda_{i}}}+0.0068 \lambda \\
\frac{1}{\lambda_{i}}=\frac{1}{\lambda+0.08 \beta}-\frac{0.035}{\beta^{3}+1} \\
\lambda=\frac{R \omega_{r}}{V_{w}} \\
\frac{d \omega_{r}}{d t}=J^{-1} P\left[T_{m}-T_{e}\right]
\end{gathered}
$$

where $P_{w}$ is the mechanical power captured by the wind turbine, $V_{w}$ is the wind speed, $C_{p}$ is the power coefficient, $\rho$ is the air density, $R$ is the radius of the wind turbine, $\omega_{r}$ is the angular speed of the wind turbine, the tip-speed ratio is represented by $\lambda, \beta$ is the pitch angle, $J$ is the inertia of the mechanical shaft, $P$ is the number of pole pairs, and $T_{e}$ and $T_{m}$ are the electrical and mechanical torque, respectively.

\subsection{Modeling of the PMSG}

The mechanical energy captured by the wind turbine is converted to electrical energy by the PMSG. The voltage and the torque dynamics of the PMSG in the d-q reference frame are as follows [42]:

$$
\begin{aligned}
V_{d s} & =L_{d} \frac{d I_{d s}}{d t}-\omega_{r} L_{q} I_{q s}+R_{s} I_{d s} \\
V_{q s} & =L_{q} \frac{d I_{q s}}{d t}+\omega_{r} L_{d} I_{d s}+\omega_{r} \Lambda_{r}+R_{s} I_{q s} \\
T_{e} & =\frac{3 P}{2}\left[\left(L_{d}-L_{q}\right) I_{d s} I_{q s}+\Lambda_{r} I_{q s}\right]
\end{aligned}
$$


where $V_{d s}$ and $v_{q s}$ are the $d$-axis and $q$-axis stator voltages, respectively, $L_{d}$ and $L_{q}$ are the $d$-axis and $q$-axis self-inductances, respectively, $I_{d s}$ and $I_{q s}$ are the $d$-axis and $q$-axis stator currents, respectively, $L_{q}$ is the $q$-axis self inductance, $\Lambda_{r}$ is the rotor flux, and $R_{s}$ is the stator resistance. For the nonsalient PMSG, $L_{d}=L_{q}$. Then, the expression for $T_{e}$ becomes:

$$
T_{e}=\frac{3 P}{2} \Lambda_{r} I_{q s}
$$

\subsection{Modeling of BES}

In this work, a lithium-ion battery was utilized for the energy storage task. A bidirectional buck/boost converter was utilized to connect the battery with the DC-link as shown in Figure 1. The bidirectional buck/boost converter behaves as buck converter when charging and as a boost converter when supplying the load. The dynamic model of the battery is given by:

$$
L_{b} \frac{d I_{b}}{d t}=\left(V_{b}-I_{b} R_{b}-D V_{d c}\right)
$$

where $L_{b}$ is the battery inductance, $I_{b}$ is the battery current, $V_{b}$ is the battery voltage, $V_{d c}$ is the DC-link voltage, and $D$ is the duty cycle of the battery buck/boost.

The dynamics of the battery state-of-charge (SOC) is expressed as [20]:

$$
\frac{d(S O C)}{d t}=-\frac{\eta_{b}}{Q_{b}} I_{b}
$$

where $Q_{b}$ and $\eta_{b}$ stand for the battery capacity and efficiency, respectively. To maintain the health of the battery, the SOC is constrained by the minimum SOC (SOC ${ }^{\mathrm{min}}$ ) and the maximum SOC (SOC $\left.{ }^{\max }\right)$ as follows:

$$
S O C^{\min }<S O C<S O C^{\max }
$$

\subsection{Modeling of the PV Module}

The PV module $\mathrm{i}$ formed by the arrangement of PV cells (consisting of $\mathrm{n}$ - and p-type semiconductor materials) in a framework. The PV cells generate DC voltage from the solar radiation. The PV cell equivalent circuit comprises a current source, a diode, a series resistor, and a parallel resistor. The output current of the PV is given by [43]:

$$
I_{p v}=N_{p}\left(I_{p h}-I_{s}\left[\exp \left(\frac{q V_{d i o}}{N_{s} A k_{B} T}\right)-1\right]-\frac{V_{d i o}}{R_{s h}}\right)
$$

where:

$$
V_{\text {dio }}=\frac{V_{p v}+I_{p v} \frac{N_{s}}{N_{p}} R_{s e}}{N_{s}}
$$

where $I_{p h}$ is the photo-generated current, $I_{p v}$ is the PV output current, $I_{S}$ is the reverse saturation current, $N_{s}$ and $N_{p}$ are the number of series- and parallel-connected PV cells, $q$ is the electron charge, $V_{d i o}$ is the diode voltage, $A$ represents the $\mathrm{p}-\mathrm{n}$ junction factor, $k_{B}$ represents the Boltzmann constant, $T$ is the cell temperature, and $R_{s e}$ and $R_{s h}$ are the equivalent series and shunt resistances, respectively.

The MPPT operation of the solar PV system at different irradiance levels was realized using the advanced multi-sector perturb and observe approach [13]. The corresponding MPPT voltage $V_{p v}^{M P P T}$ and current $I_{p v}^{M P P T}$ are computed simultaneously. The MPPT voltage, $V_{p v}^{M P P T}$ was set as the reference voltage for the DC-link $V_{d c}^{*}$. However, when the irradiance level is very low (at night), $V_{p v}^{M P P T}$ is also very low (below the minimum allowable DC-link voltage), and the MPPT controller sets $V_{d c}^{*}$ as the nominal DC-link voltage. On the other 
hand, when the irradiance level is too high, $V_{p v}^{M P P T}$ is also high. If $V_{p v}^{M P P T}$ is greater than the allowable maximum DC-link voltage, the MPPT controller sets $V_{d c}^{*}$ as the nominal DC voltage.

\subsection{Modeling of the DC-Link}

The power generated from the renewable sources is transferred to the grid-side inverter through the DC-link. The dynamic model of the DC-link voltage is derived at the DC-link node shown in Figure 1 as follows:

$$
C_{d c} \frac{d V_{d c}}{d t}=I_{s d c}+I_{p v}+(1-D) I_{b}-I_{g d c}
$$

where $I_{s d c}$ is the output DC current of the the RSC, $V_{b}$ is the battery voltage, $D$ is the duty cycle, $C_{d c}$ is the capacitance of the DC-bus, and $I_{g d c}$ is the input DC current of the GSC.

Assuming that the RSC and GSC are ideal, the following relations are valid.

$$
P_{w}=I_{s d c} V_{d c} ; \quad I_{g d c} V_{d c}=\frac{3}{2} V_{d} I_{d}
$$

where $I_{d}$ and $V_{d}$ are the $d$-axis AC current and AC voltage of the GSC, respectively.

Using (24), the DC voltage dynamic equation can be rewritten as:

$$
C_{d c} \frac{d V_{d c}}{d t}=\frac{P_{w}}{V_{d c}}+I_{p v}+(1-D) I_{b}-\frac{3}{2} \frac{V_{d} I_{d}}{V_{d c}}
$$

\subsection{Modeling of the GSC}

The GSC converts the DC signals from the DC-link into three-phase AC signals. The GSC is utilized to (a) regulate the DC-link voltage, (b) achieve the MPPT performance of the solar PV system, (c) ensure power transfer from the DC side to the AC grid side, and (d) regulate the active and reactive power at the grid side. A cascade control structure was designed to perform these tasks. The dynamic equations of the GSC in the d-q reference frame are as follows:

$$
\begin{aligned}
& V_{d}=U_{d}-L_{f} \omega_{g} I_{q}+R_{f} I_{d}+L_{f} \frac{d I_{d}}{d t} \\
& V_{q}=U_{q}+L_{f} \omega_{g} I_{d}+R_{f} I_{q}+L_{f} \frac{d I_{q}}{d t}
\end{aligned}
$$

where $I_{q}$ and $V_{q}$ are the $q$-axis AC current and voltage of the GSC, respectively, $U_{d}$ and $U_{q}$ are the $d$-axis and $q$-axis voltages at the point of common coupling (PCC), $L_{f}$ and $R_{f}$ are the grid-side filter inductance and resistance, respectively, and $\omega_{g}$ is the electrical angular speed.

\section{GSMCFO Method for the Hybrid Microgrid}

This section presents the proposed GFOSMC scheme for the hybrid microgrid. The section is divided into three subsections: RSC control, buck/boost converter control, and GSC control subsections.

\subsection{RSC Control}

The aim of the RSC control is to generate pulse width modulation signals to track the optimum operating point of the rotor to harness the maximum wind power. An advance multi-sector perturb and observe scheme was used to determine the MPPT of the rotor [13]. The optimum rotor speed is given by:

$$
\omega_{r}^{*}=\frac{\lambda_{o p t} V_{w}}{R}
$$


where $\lambda_{\text {opt }}$ is the optimum tip speed ratio at the point where $C_{p}(\lambda, \beta)$ is maximum for any given wind speed. The optimum rotor speed is the desired speed of the rotor controller.

In order to minimize the stator iron loss and maximize the PMSG efficiency, the desired $d$-axis stator current was set to zero $\left(I_{d s}^{*}=0\right)[44]$.

The tracking errors for the rotor speed $e_{1}$ and $d$-axis stator current $e_{2}$ are given by:

$$
\begin{aligned}
& e_{1}(t)=\omega_{r}(t)-\omega_{r}^{*}(t) \\
& e_{2}(t)=I_{d s}(t)-I_{d s}^{*}(t)
\end{aligned}
$$

Then, we can obtain the following:

$$
\begin{aligned}
\dot{e}_{1}(t) & =\frac{P}{J}\left[T_{m}-T_{e}\right]-\dot{\omega}_{r}^{*}(t) \\
\ddot{e}_{1}(t) & =a\left[L_{q} \omega_{r} I_{d s}+R_{s} I_{q s}+\lambda_{r} \omega_{r}\right]+a V_{q s}+H_{1}-\ddot{\omega}_{r}^{*}(t) \\
\dot{e}_{2} & =\frac{1}{L_{d}}\left[L_{q} \omega_{r} I_{q s}-R_{s} I_{d s}\right]+\frac{1}{L_{d}} V_{d s}+H_{2}-I_{d s}^{*}(t)
\end{aligned}
$$

where $a=\frac{3 P^{2} \Lambda_{r}}{2 J L_{q}}, H_{i}(i=1,2)$ are the lumped disturbances in the system.

From the equations above, it can be seen that $\omega_{r}$ and $I_{d s}$ have a relative degree of two and one, respectively. The proposed fractional-order sliding-mode surface for $\omega_{r}$ is given as follows [40]:

$$
\zeta_{1}(t)=k_{1}{ }^{R} \mathcal{I}_{t}^{\mu} e_{1}(t)+\sigma_{1}{ }^{R} \mathcal{D}_{t}^{1-\mu} e_{1}(t)+{ }^{R} \mathcal{D}_{t}^{2-\mu} e_{1}(t)
$$

and the fractional-order sliding-mode surface for $I_{d s}$ is given by:

$$
\zeta_{2}(t)=k_{2}{ }^{R} \mathcal{I}_{t}^{\mu} e_{2}(t)+{ }^{R} \mathcal{D}_{t}^{1-\mu} e_{2}(t)
$$

where $\mu \in(0,1), k_{i},(1,2)$, and $\sigma_{1}$ are positive constants. Utilizing Properties $1-3$, the Riemann-Liouville fractional derivatives of $\zeta_{1}$ and $\zeta_{2}$ yield:

$$
\begin{aligned}
& { }^{R} \mathcal{D}_{t}^{\mu} \zeta_{1}(t)=k_{1} e_{1}(t)+\sigma_{1} \dot{e}_{1}(t)+\ddot{e}_{1}(t) \\
& { }^{R} \mathcal{D}_{t}^{\mu} \zeta_{2}(t)=k_{2} e_{2}(t)+\dot{e}_{2}(t)
\end{aligned}
$$

Inserting (32) and (33) into (36) and (37), respectively, we obtain:

$$
\begin{gathered}
{ }^{R} \mathcal{D}_{t}^{\mu} \zeta_{1}(t)=k_{1} e_{1}(t)+\sigma_{1} \dot{e}_{1}(t)+H_{1}+a\left[L_{q} \omega_{r} I_{d s}+R_{s} I_{q s}+\lambda_{r} \omega_{r}\right]+a V_{q s}-\ddot{\omega}_{r}^{*} \\
{ }^{R} \mathcal{D}_{t}^{\mu} \zeta_{2}(t)=k_{2} e_{2}(t)+\frac{1}{L_{d}}\left[L_{q} \omega_{r} I_{q s}-R_{s} I_{d s}\right]+\frac{V_{d s}}{L_{d}}+H_{2}-\dot{I}_{d s}^{*}
\end{gathered}
$$

Considering Assumption 1, the equivalent control signals of the rotor speed and $d$-axis stator current that eliminate the terms on the right-hand side of (38) and (39) are respectively designed as follows:

$$
\begin{gathered}
V_{q s_{-} e q v}=-\frac{1}{a}\left(\begin{array}{c}
k_{1} e_{1}(t)+\sigma_{1} \dot{e}_{1}(t)+{ }^{R} \mathcal{I}_{t}^{1-\mu} \delta_{1}-\ddot{\omega}_{r}^{*} \\
+a\left[L_{q} \omega_{r} I_{d s}+R_{s} I_{q s}+\lambda_{r} \omega_{r}\right]
\end{array}\right) \\
V_{d s_{-} e q v}=-L_{d}\left(\begin{array}{c}
k_{2} e_{2}(t)+\frac{\left[L_{q} \omega_{r} I_{q s}-R_{s} I_{d s}\right]}{L_{d}} \\
+{ }^{R} \mathcal{I}_{t}^{1-\mu} \delta_{2}-\dot{I}_{d s}^{*}
\end{array}\right)
\end{gathered}
$$


The control signals that guarantee $\omega_{r}$ and $I_{d s}$ effectively arrive and stay on the slidingmode surfaces in the presence of external disturbances, parametric perturbation, and unknown dynamics designed as follows:

$$
\begin{gathered}
V_{q s}=V_{q s_{-} \text {eqv }}-\frac{1}{a}\left[\varrho_{1}{ }^{R} \mathcal{I}_{t}^{1-\mu}{ }_{s g n^{\alpha}} \zeta_{1}(t)+\gamma_{1}{ }^{R} \mathcal{I}_{t}^{1-\mu} \zeta_{1}(t)\right] \\
V_{d s}=V_{d s_{-} \text {eqv }}-L_{d}\left[\varrho_{2}{ }^{R} \mathcal{I}_{t}^{1-\mu}{ }_{s g n^{\alpha}} \zeta_{2}(t)+\gamma_{2}{ }^{R} \mathcal{I}_{t}^{1-\mu} \zeta_{2}(t)\right]
\end{gathered}
$$

where $\alpha \in(0,1), \varrho_{1}$ and $\gamma_{i}(i=1,2)$ are positive constants, and $\operatorname{sgn}^{\alpha} \zeta_{i}(t)=\operatorname{sgn}\left(\zeta_{i}(t)\right)\left|\zeta_{i}(t)\right|^{\alpha}$.

\subsection{GSC Control}

The aims of the GSC control are: (1) the MPPT operation of the PV system, (2) regulating the DC-link voltage for the proper transmission of power to the grid, and (3) regulating the active and reactive powers at the grid side. A cascade control structure was implemented for the GSC to realize these objectives. Define the DC-link voltage regulation tracking error as follows:

$$
e_{3}(t)=V_{d c}(t)-V_{d c}^{*}(t)
$$

The time derivative of $e_{3}(t)$ gives:

$$
\dot{e}_{3}(t)=\frac{P_{w}}{C_{d c} V_{d c}}+\frac{I_{p v}}{C_{d c}}+\frac{(1-D)}{C_{d c}} I_{b}-\frac{3}{2} \frac{V_{d} I_{d}}{C_{d c} V_{d c}}+H_{3}-\dot{V}_{d c}^{*}(t)
$$

where $H_{3}$ is the additive lumped disturbance in the system. The FOSM surface for the $V_{d c}$ dynamics is expressed as follows:

$$
\zeta_{3}(t)=k_{3}{ }^{R} \mathcal{I}_{t}^{\mu} e_{3}(t)+{ }^{R} \mathcal{D}_{t}^{1-\mu} e_{3}(t)
$$

where $\mu \in(0,1)$ and $k_{3}$ are a positive constants. The Riemann-Liouville fractional derivative of $\zeta_{3}$ gives:

$$
\mathcal{D}_{t}^{\mu} \zeta_{3}(t)=k_{3} e_{3}(t)+\dot{e}_{3}(t)
$$

Inserting (45) into (47), we obtain:

$$
{ }^{R} \mathcal{D}_{t}^{\mu} \zeta_{3}(t)=k_{3} e_{3}(t)+\frac{P_{w}}{C_{d c} V_{d c}}+\frac{I_{p v}}{C_{d c}}+\frac{(1-D)}{C_{d c}} I_{b}+H_{3}-\dot{V}_{d c}^{*}(t)
$$

Considering Assumption 1, the equivalent control signal of the DC-link voltage is designed as follows:

$$
I_{d_{-} e q v}=\frac{2}{3} \frac{C_{d c} V_{d c}}{V_{d}}\left(\begin{array}{c}
k_{3} e_{3}(t)+\frac{P_{w}}{C_{d c} V_{d c}}+\frac{I_{p v}}{C_{d c}} \\
+\frac{(1-D)}{C_{d c}} I_{b}+{ }^{R} \mathcal{I}_{t}^{1-\mu} \delta_{3}-\dot{V}_{d c}^{*}(t)
\end{array}\right)
$$

The control signal that makes $e_{3}$ properly reach and remain on the surface $\zeta_{3}=0$ in the presence of external disturbances, parametric perturbation, and unknown dynamics is given by:

$$
I_{d}=I_{d \_e q v}-\frac{2}{3} \frac{C_{d c} V_{d c}}{V_{d}}\left[\varrho_{3} \mathcal{I}_{t}^{1-\mu}{ }_{s g n^{\alpha}} \zeta_{3}(t)+\gamma_{3} \mathcal{I}_{t}^{1-\mu} \zeta_{3}(t)\right]
$$

where $\alpha \in(0,1), \varrho_{3}$ and $\gamma_{3}$ are positive constants, and $\operatorname{sgn}{ }^{\alpha} \zeta_{3}(t)=\operatorname{sgn}\left(\zeta_{3}(t)\right)\left|\zeta_{3}(t)\right|^{\alpha}$. 
The output AC currents of the GSC are controlled for proper power transfer to the AC side. The active power is controlled by the $d$-axis AC current, and $I_{d}^{*}=I_{d}$ is set as the desired current. The reactive power is desired to be very close to zero by controlling the $q$-axis current and setting the desired $q$-axis current as $I_{q}^{*}=0$.

The tracking errors for the $d$-axis current $e_{4}$ and $q$-axis stator current $e_{5}$ are given by:

$$
\begin{aligned}
& e_{4}(t)=I_{d}(t)-I_{d}^{*}(t) \\
& e_{5}(t)=I_{q}(t)-I_{q}^{*}(t)
\end{aligned}
$$

Then, we can obtain the following:

$$
\begin{aligned}
& \dot{e}_{4}(t)=\frac{1}{L_{f}}\left[V_{d}-R_{f} I_{d}-U_{d}+L_{f} \omega_{g} I_{q}\right]+H_{4}-\dot{I}_{d}^{*}(t) \\
& \dot{e}_{5}(t)=\frac{1}{L_{f}}\left[V_{d q}-R_{f} I_{q}-U_{q}-L_{f} \omega_{g} I_{d}\right]+H_{5}-\dot{I}_{q}^{*}(t)
\end{aligned}
$$

where $H_{i}(i=4,5)$ are the lumped disturbances in the system. The fractional-order sliding mode surfaces for the GSC are defined as follows:

$$
\begin{aligned}
& \zeta_{4}(t)=k_{4}{ }^{R} \mathcal{I}_{t}^{\mu} e_{4}(t)+{ }^{R} \mathcal{D}_{t}^{1-\mu} e_{4}(t) \\
& \zeta_{5}(t)=k_{5}{ }^{R} \mathcal{I}_{t}^{\mu} e_{5}(t)+{ }^{R} \mathcal{D}_{t}^{1-\mu} e_{5}(t)
\end{aligned}
$$

where $\mu \in(0,1)$ and $k_{i},(4,5)$ are positive constants. The Riemann-Liouville fractional derivative of $\zeta_{4}$ and $\zeta_{5}$ give:

$$
\begin{aligned}
& { }^{R} \mathcal{D}_{t}^{\mu} \zeta_{4}(t)=k_{4} e_{4}(t)+\dot{e}_{4}(t) \\
& { }^{R} \mathcal{D}_{t}^{\mu} \zeta_{5}(t)=k_{5} e_{5}(t)+\dot{e}_{5}(t)
\end{aligned}
$$

Substituting (53) and (54) into (55) and (56), respectively, one has:

$$
\begin{aligned}
& { }^{R} \mathcal{D}_{t}^{\mu} \zeta_{4}(t)=k_{4} e_{4}(t)-\dot{I}_{d}^{*}+\frac{1}{L_{f}}\left[V_{d}-R_{f} I_{d}-U_{d}+L_{f} \omega_{g} I_{q}+H_{4}\right] \\
& { }^{R} \mathcal{D}_{t}^{\mu} \zeta_{5}(t)=k_{5} e_{5}(t)-\dot{I}_{q}^{*}+\frac{1}{L_{f}}\left[V_{q}-R_{f} I_{q}-U_{q}-L_{f} \omega_{g} I_{d}+H_{5}\right]
\end{aligned}
$$

Considering Assumption 1, the equivalent control signals of the GSC are expressed as follows:

$$
\begin{gathered}
V_{d_{-} e q v}=-L_{f}\left(\begin{array}{c}
k_{4} e_{4}(t)-\dot{I}_{d}^{*} \\
-\frac{1}{L_{f}}\left[R_{f} I_{d}+U_{d}-L_{f} \omega_{g} I_{q}+{ }^{R} \mathcal{I}_{t}^{1-\mu} \delta_{4}\right]
\end{array}\right) \\
V_{q_{-} e q v}=-L_{f}\left(\begin{array}{c}
k_{5} e_{5}(t)-\dot{I}_{q}^{*} \\
-\frac{1}{L_{f}}\left[R_{f} I_{q}+U_{q}+L_{f} \omega_{g} I_{d}+{ }^{R} \mathcal{I}_{t}^{1-\mu} \delta_{5}\right]
\end{array}\right)
\end{gathered}
$$

The control signals for reaching and staying on $\zeta_{4}$ and $\zeta_{5}$ are thus:

$$
\begin{aligned}
& V_{d}=V_{d_{-} e q v}-L_{f}\left[\varrho_{4}{ }^{R} \mathcal{I}_{t}^{1-\mu}{ }^{s g n^{\alpha}} \zeta_{4}(t)+\gamma_{4}{ }^{R} \mathcal{I}_{t}^{1-\mu} \zeta_{4}(t)\right] \\
& V_{q}=V_{q_{-} e q v}-L_{f}\left[\varrho_{5}{ }^{R} \mathcal{I}_{t}^{1-\mu}{ }^{s g n^{\alpha}} \zeta_{5}(t)+\gamma_{5}{ }^{R} \mathcal{I}_{t}^{1-\mu} \zeta_{5}(t)\right]
\end{aligned}
$$


where $\alpha \in(0,1), \varrho_{i}$ and $\gamma_{i}(i=4,5)$ are positive constants, and $\operatorname{sgn} n^{\alpha} \zeta_{i}(t)=\operatorname{sgn}\left(\zeta_{i}(t)\right)\left|\zeta_{i}(t)\right|^{\alpha}$.

\subsection{Buck/Boost Converter Control}

The objective of the buck/boost control is to facilitate efficient battery charging/discharging to maintain the power balance of the hybrid microgrid. The desired battery current $I_{b}^{*}$ is obtained based on the net power in the system. The battery charge/discharge power $P_{b}$ is given by:

$$
P_{b}=P_{g e n}-P_{d e m}
$$

where $P_{d e m}$ is the load/demand power of the consumers, $P_{g e n}=\left(P_{w}+P_{p v}+P_{u g}\right)$ is the total generated power, and $P_{u g}$ is the utility grid power. $P_{u g}$ is bidirectional, i.e, it can transfer power to the load when the battery cannot discharge or absolve excess power generated when the battery is fully charged. $P_{u g}>0$ when transferring power, and $P_{u g}<0$ when receiving power. The main aim of the battery controller is to guarantee that the power deviation/imbalance $\Delta P$ is zero.

$$
\Delta P=P_{b}-\left(P_{\text {gen }}-P_{\text {dem }}\right) \longrightarrow 0
$$

The reference battery current is calculated as follows:

$$
I_{b}^{*}=\frac{P_{g e n}-P_{\text {dem }}}{V_{b}}
$$

The battery tracking error is defined as:

$$
e_{6}(t)=I_{b}(t)-I_{b}^{*}(t)
$$

The time derivative of $e_{6}$ gives:

$$
\dot{e}_{6}=\frac{d I_{b}}{d t}=\frac{1}{L_{b}}\left(V_{b}-I_{b} R_{b}-D V_{d c}+H_{6}\right)-\dot{I}_{b}^{*}(t)
$$

where $\mathrm{H}_{6}$ is the lumped disturbance in the system. Following the same procedure as the previous subsections, the battery controller is designed as follows:

$$
\begin{gathered}
D_{\text {eqv }}=\frac{L_{b}}{V_{d c}}\left(K_{6} e_{6}(t)+\frac{V_{b}}{L_{b}}-\frac{I_{b} R_{b}}{L_{b}}+{ }^{R} \mathcal{I}_{t}^{1-\mu} \delta_{6}-\dot{I}_{b}^{*}\right) \\
D=D_{\text {eqv }}-L_{b}\left[\varrho_{6}{ }^{R} \mathcal{I}_{t}^{1-\mu}{ }^{1-\mu} n^{\alpha} \zeta_{6}(t)+\gamma_{6}{ }^{R} \mathcal{I}_{t}^{1-\mu} \zeta_{6}(t)\right]
\end{gathered}
$$

where $\alpha \in(0,1), \varrho_{6}$ and $\gamma_{6}$ are positive constants, and $\operatorname{sgn}^{\alpha} \zeta_{6}(t)=\operatorname{sgn}\left(\zeta_{6}(t)\right)\left|\zeta_{6}(t)\right|^{\alpha}$.

Remark 1. The high-frequency switching of the discontinuous functions $\operatorname{sgn}\left(\zeta_{i}\right)(i=1,2, \ldots, 6)$ in (42), (43), (50), (63), (64), and (71) cause chattering, which is the main disadvantage of conventional SMC. This drawback was tackled by replacing the signum function with a hyperbolic tangent function $\tanh \left(\frac{\zeta_{i}}{\vartheta}\right)$.

The modified control inputs are given as follows:

$$
\begin{gathered}
V_{q s}=V_{q s_{-} e q v}-\frac{1}{a}\left[\varrho_{1}{ }^{R} \mathcal{I}_{t}^{1-\mu} \tanh \left(\frac{\zeta_{1}}{\vartheta}\right)\left|\zeta_{1}(t)\right|^{\alpha}+\gamma_{1}{ }^{R} \mathcal{I}_{t}^{1-\mu} \zeta_{1}(t)\right] \\
V_{d s}=V_{d s_{-} e q v}-L_{d}\left[\varrho_{2}{ }^{R} \mathcal{I}_{t}^{1-\mu} \tanh \left(\frac{\zeta_{2}}{\vartheta}\right)\left|\zeta_{2}(t)\right|^{\alpha}+\gamma_{2}{ }^{R} \mathcal{I}_{t}^{1-\mu} \zeta_{2}(t)\right]
\end{gathered}
$$




$$
\begin{gathered}
I_{d}=I_{d \_ \text {eqv }}-\frac{2}{3} \frac{C_{d c} V_{d c}}{V_{d}}\left[\varrho_{3} \mathcal{I}_{t}^{1-\mu} \tanh \left(\frac{\zeta_{3}}{\vartheta}\right)\left|\zeta_{3}(t)\right|^{\alpha}+\gamma_{3} \mathcal{I}_{t}^{1-\mu} \zeta_{3}(t)\right] \\
V_{d}=V_{d \_e q v}-L_{f}\left[\varrho_{4}{ }^{R} \mathcal{I}_{t}^{1-\mu} \tanh \left(\frac{\zeta_{4}}{\vartheta}\right)\left|\zeta_{4}(t)\right|^{\alpha}+\gamma_{4}{ }^{R} \mathcal{I}_{t}^{1-\mu} \zeta_{4}(t)\right] \\
V_{q}=V_{q_{-} e q v}-L_{f}\left[\varrho_{5}{ }^{R} \mathcal{I}_{t}^{1-\mu} \tanh \left(\frac{\zeta_{5}}{\vartheta}\right)\left|\zeta_{5}(t)\right|^{\alpha}+\gamma_{5}{ }^{R} \mathcal{I}_{t}^{1-\mu} \zeta_{5}(t)\right] \\
D=D_{\text {eqv }}-L_{b}\left[\varrho_{6}{ }^{R} \mathcal{I}_{t}^{1-\mu} \tanh \left(\frac{\zeta_{6}}{\vartheta}\right)\left|\zeta_{6}(t)\right|^{\alpha}+\gamma_{6}{ }^{R} \mathcal{I}_{t}^{1-\mu} \zeta_{6}(t)\right]
\end{gathered}
$$

Theorem 1. If the GSMCFOs are designed as (72)-(77), the sliding-mode surfaces $\zeta_{i}(i=1,2, \ldots$, 6) will converge to zero within a finite time.

Proof. A Lyapunov function candidate is selected as:

$$
L=\frac{\zeta_{1}^{2}(t)}{2}+\frac{\zeta_{2}^{2}(t)}{2}+\frac{\zeta_{3}^{2}(t)}{2}+\frac{\zeta_{4}^{2}(t)}{2}+\frac{\zeta_{5}^{2}(t)}{2}+\frac{\zeta_{6}^{2}(t)}{2}
$$

Differentiating $L$ with respect to time gives:

$$
\dot{L}=\sum_{i=1}^{6} \zeta_{i}(t) \dot{\zeta}_{i}(t)=\sum_{i=1}^{6} \zeta_{i}(t){ }^{R} \mathcal{D}_{t}^{1-\mu}\left({ }^{R} \mathcal{D}_{t}^{\mu} \zeta_{i}(t)\right)
$$

Substituting (72)-(77) into (79), one obtains:

$$
\begin{aligned}
\dot{L} & =\sum_{i=1}^{6} \zeta_{i}(t)^{R} \mathcal{D}_{t}^{1-\mu}\left(\begin{array}{c}
H_{i}-{ }^{R} \mathcal{I}_{t}^{1-\mu} \delta_{i} \\
-\varrho_{i}{ }^{R} \mathcal{I}_{t}^{1-\mu} s g n^{\alpha} \zeta_{i}(t)-\gamma_{i}{ }^{R} \mathcal{I}_{t}^{1-\mu} \zeta_{i}(t)
\end{array}\right) \\
& =\sum_{i=1}^{6} \zeta_{i}\left(\begin{array}{c}
{ }^{R} \mathcal{D}_{t}^{1-\mu} H_{i}-\delta_{i} \\
-\varrho_{i} \tanh \left(\frac{\zeta_{5}}{\vartheta}\right)\left|\zeta_{5}(t)\right|^{\alpha}-\gamma_{i} \zeta_{i}(t)
\end{array}\right) \\
& =\sum_{i=1}^{6}\left(\begin{array}{c}
\zeta_{i}\left({ }^{R} \mathcal{D}_{t}^{1-\mu} H_{i}-\delta_{i}\right) \\
-\varrho_{i} \tanh \left(\frac{\zeta_{i}}{\vartheta}\right)\left|\zeta_{i}(t)\right|^{\alpha+1}-\gamma_{i} \zeta_{i}^{2}(t)
\end{array}\right)
\end{aligned}
$$

Based on Assumption 1, we have:

$$
\dot{L} \leq-\sum_{i=1}^{6} \varrho_{i}\left|\tanh \left(\frac{\zeta_{i}}{\vartheta}\right)\right|\left|\zeta_{i}(t)\right|^{\alpha+1}-\sum_{i=1}^{6} \gamma_{i}\left|\zeta_{i}(t)\right|^{2}
$$

Therefore, we obtain:

$$
\dot{L} \leq-\sum_{i=1}^{6} \varrho_{i}\left|\zeta_{i}(t)\right|^{\alpha+1}
$$

The above inequality can be rewritten as follows:

$$
\dot{L} \leq-\sum_{i=1}^{6} \varrho_{i}\left\|\zeta_{i}(t)\right\|_{2}^{\alpha+1}
$$

Consequently, it can be concluded that all the states' trajectories will converge to their respective sliding-mode surfaces $\zeta_{i}=0(i=1,2, \ldots, 6)$. 
From (81), one has:

$$
\frac{d L}{d t} \leq-\varrho_{i}(2 L)^{\frac{\alpha+1}{2}}-\gamma_{i}(2 L)
$$

Rearranging (84) yields:

$$
\begin{aligned}
d t & \leq-\frac{d L}{\varrho_{i}(2 L)^{\frac{\alpha+1}{2}}+\gamma_{i}(2 L)}=-\frac{1}{2} \frac{(2 L)^{-\frac{1}{2}} d(2 L)}{\varrho_{i}(2 L)^{\frac{\alpha}{2}}+\gamma_{i}(2 L)^{\frac{1}{2}}} \\
& \leq-\frac{d(2 L)^{\frac{1}{2}}}{\varrho_{i}(2 L)^{\frac{\alpha}{2}}+\gamma_{i}(2 L)^{\frac{1}{2}}}=-\frac{d\left\|\zeta_{i}(t)\right\|_{2}}{\varrho_{i}\left\|\zeta_{i}(t)\right\|_{2}^{\alpha}+\gamma_{i}\left\|\zeta_{i}(t)\right\|_{2}} \\
& \leq-\frac{\left\|\zeta_{i}(t)\right\|_{2}^{-\alpha} d\left\|\zeta_{i}(t)\right\|_{2}}{\varrho_{i}+\gamma_{i}\left\|\zeta_{i}(t)\right\|_{2}^{1-\alpha}} \\
& \leq-\frac{1}{\gamma_{i}(1-\alpha)} \frac{d\left(\gamma_{i}\left\|\zeta_{i}(t)\right\|_{2}^{1-\alpha}\right)}{\varrho_{i}+\gamma_{i}\left\|\zeta_{i}(t)\right\|_{2}^{1-\alpha}}
\end{aligned}
$$

Integrating both sides of (85) from zero to $t_{r}$ yields:

$$
\begin{aligned}
t_{r}-0 & \leq-\frac{1}{\gamma_{i}(1-\alpha)} \int_{0}^{t_{r}} \frac{d\left(\gamma_{i}\left\|\zeta_{i}(t)\right\|_{2}^{1-\alpha}\right)}{\varrho_{i}+\gamma_{i}\left\|\zeta_{i}(t)\right\|_{2}^{1-\alpha}} \\
& \leq-\left.\frac{1}{\gamma_{i}(1-\alpha)} \ln \left(\varrho_{i}+\gamma_{i}\left\|\zeta_{i}(t)\right\|_{2}^{1-\alpha}\right)\right|_{0} ^{t_{r}} \\
& \leq \frac{1}{\gamma_{i}(1-\alpha)} \ln \left(1+\frac{\gamma_{i}}{\varrho_{i}}\left\|\zeta_{i}(0)\right\|_{2}^{1-\alpha}\right)
\end{aligned}
$$

Hence, the states' trajectories will arrive at their respective sliding manifolds $\zeta_{i}=$ $0(i=1,2, \ldots, 6)$ within a finite time given by:

$$
T_{r}=t_{r}-0 \leq \frac{1}{\gamma_{i}(1-\alpha)} \ln \left(1+\frac{\gamma_{i}}{\varrho_{i}}\left\|\zeta_{i}(0)\right\|_{2}^{1-\alpha}\right)
$$

\section{Simulation Results}

The presented hybrid microgrid configuration was implemented in MATLAB/SIMULINK. The parameters of the PMSG, wind turbine, solar PV, BES, and grid are provided in Tables 1 and 2. To improve the efficiency, longevity, and reliability of the BES, the minimum SOC was set as $S O C^{\text {min }}=20 \%$, while the maximum SOC was set as $S O C^{\max }=90 \%$. The optimized parameters of the proposed GSMCFO achieved by the DE are given in Table 3: Four scenarios are provided to validate the efficacy of the proposed hybrid microgrid configuration and the control scheme.

Table 1. Parameters of the renewable generation system.

\begin{tabular}{cccccc}
\hline \multicolumn{2}{c}{ Wind Turbine Generator [43] } & \multicolumn{2}{c}{ Solar PV Generator [42] } \\
\hline Parameter & Symbol & Value & Parameter & Symbol & Value \\
\hline $\begin{array}{c}\text { Air density } \\
\left(\mathrm{kg} / \mathrm{m}^{3}\right)\end{array}$ & $\rho$ & 1.25 & $\begin{array}{c}\text { Ambient } \\
\text { temperature }(\mathrm{C})\end{array}$ & $T$ & 25 \\
\hline $\begin{array}{c}\text { Radius of wind } \\
\text { turbine }(\mathrm{m})\end{array}$ & $R$ & 28.2 & & \\
\hline $\begin{array}{c}\text { d-axis stator } \\
\text { current }(\mathrm{mH})\end{array}$ & $L_{d s}$ & 9.8 & $\begin{array}{c}\text { p-n junction } \\
\text { factor }\end{array}$ & $A$ & 1.8 \\
\hline
\end{tabular}


Table 1. Cont.

\begin{tabular}{|c|c|c|c|c|c|}
\hline \multicolumn{3}{|c|}{ Wind Turbine Generator [43] } & \multicolumn{3}{|c|}{ Solar PV Generator [42] } \\
\hline Parameter & Symbol & Value & Parameter & Symbol & Value \\
\hline $\begin{array}{l}q \text {-axis stator } \\
\text { current }(\mathrm{mH})\end{array}$ & $L_{q s}$ & 9.8 & $\begin{array}{l}\text { Equivalent shunt } \\
\text { resistor }(\Omega)\end{array}$ & $R_{s h}$ & 313.33 \\
\hline $\begin{array}{l}\text { Rotor flux } \\
\qquad(\mathrm{Wb})\end{array}$ & $\Lambda_{r}$ & 28 & $\begin{array}{l}\text { Equivalent series } \\
\text { resistor }(\Omega)\end{array}$ & $R_{s e}$ & 0.193 \\
\hline $\begin{array}{c}\text { Inertia of mechanical } \\
\text { shaft }\left(\mathrm{Kg} \cdot \mathrm{m}^{2}\right)\end{array}$ & $J$ & 4000 & $\begin{array}{l}\text { Short-circuit } \\
\text { current (A) }\end{array}$ & $I_{s c}$ & 2.8 \\
\hline $\begin{array}{l}\text { Number of } \\
\text { pole pairs }\end{array}$ & $P$ & 8 & $\begin{array}{c}\text { Number of } \\
\text { parallel modules }\end{array}$ & $N_{S}$ & 68 \\
\hline $\begin{array}{l}\text { Optimum tip } \\
\text { speed ratio }\end{array}$ & $\Lambda_{o p t}$ & 8.1 & $\begin{array}{l}\text { Number of } \\
\text { series modules }\end{array}$ & $N_{p}$ & 95 \\
\hline Power coefficient & $C_{p}^{\max }$ & 0.48 & $\begin{array}{l}\text { Open-circuit } \\
\text { voltage }(V)\end{array}$ & $V_{o c}$ & 32.9 \\
\hline $\begin{array}{l}\text { Rated wind generator } \\
\text { power (MW) }\end{array}$ & $P_{w}$ & 2 & $\begin{array}{c}\text { Rated PV power (MW) } \\
\text { voltage }(\mathrm{V})\end{array}$ & $P_{p v}$ & 1 \\
\hline
\end{tabular}

Table 2. Grid and energy storage parameters [42].

\begin{tabular}{cccccc}
\hline \multicolumn{2}{c}{ Battery Energy Storage System } & \multicolumn{2}{c}{ Grid Parameter } \\
\hline Parameter & Symbol & Value & Parameter & Symbol & Value \\
\hline Battery efficiency & $\eta_{b}$ & 0.9 & $\begin{array}{c}\text { Filter inductance } \\
(\mathrm{mH})\end{array}$ & $L_{f}$ & 16.9 \\
\hline $\begin{array}{c}\text { Battery } \\
\text { capacity (AH) }\end{array}$ & $Q_{b}$ & 1000 & $\begin{array}{c}\text { Line inductance } \\
(\mathrm{mH})\end{array}$ & $L_{g}$ & 1.69 \\
\hline $\begin{array}{c}\text { Rated battery power } \\
\text { (MW) }\end{array}$ & $P_{b}$ & 1 & $\begin{array}{c}\text { Load demand } \\
(\mathrm{MW})\end{array}$ & $P_{l}$ & 2 \\
\hline $\begin{array}{c}\text { Battery voltage } \\
\text { (V) }\end{array}$ & $V_{b}$ & 550 & $\begin{array}{c}\text { Line-to-line } \\
\text { voltage }(\mathrm{V})\end{array}$ & $U_{l l}$ & 1000 \\
\hline $\begin{array}{c}\text { Upper SOC } \\
\text { limit (\%) }\end{array}$ & $S O C^{\text {max }}$ & 90 & $\begin{array}{c}\text { DC-bus } \\
\text { capacitance }(\mu \mathrm{F})\end{array}$ & $C_{d c}$ & 1670 \\
\hline $\begin{array}{c}\text { Lower SOC } \\
\text { limit (\%) }\end{array}$ & $S O C^{\text {min }}$ & 20 & & & \\
\hline
\end{tabular}

Table 3. Control system parameters.

\begin{tabular}{cccc}
\hline Parameters & Values & Parameters & Values \\
\hline$k_{1}$ & 0.0117 & $k_{4}$ & 0.0847 \\
$k_{2}$ & 0.0240 & $k_{5}$ & 0.0106 \\
$k_{3}$ & 0.1342 & $k_{6}$ & 0.2302 \\
$\varrho_{1}$ & 1.3239 & $\varrho_{4}$ & 5.6694 \\
$\varrho_{2}$ & 0.7009 & $\varrho_{5}$ & 2.0982 \\
$\varrho_{3}$ & 11.3652 & $\varrho_{6}$ & 15.7501 \\
$\gamma_{1}$ & 12.3794 & $\gamma_{4}$ & 25.0214 \\
$\gamma_{2}$ & 9.0402 & $\gamma_{5}$ & 13.0005 \\
$\gamma_{3}$ & 19.7391 & $\gamma_{6}$ & 37.4478 \\
$\alpha$ & 0.4 & $\mu$ & 0.8 \\
\hline
\end{tabular}




\subsection{Scenario 1: Power Generation from Solar PV Only}

Under Scenario 1, the wind speed is below the cut-in speed and the wind power is not large enough to overcome the mechanical resistance of the wind turbine. Therefore, the renewable power is generated by solar PV alone. As shown in Figure 2, the irradiance level drops from $1000 \mathrm{~W} / \mathrm{m}^{2}$ to $940 \mathrm{~W} / \mathrm{m}^{2}$, then increases to $1000 \mathrm{~W} / \mathrm{m}^{2}$ at $t=10 \mathrm{~s}$ and $20 \mathrm{~s}$, respectively. The MPPT voltage of the PV was set as the reference DC-link voltage. From Figure 3, the DC-link voltage decreases for $10 \leq t \leq 20$ as the irradiance level decreases at the same interval. From Figure 4, the battery stops discharging to support the PV output as it cannot discharge below the minimum SOC. The utility grid injects power to the load to maintain the power balance of the system for $26.4 \leq t \leq 40$. The power deviation $\Delta P$ reduces to zero to balance the power in the system. The battery current and SOC are presented in Figure 5. For $26.4 \leq t \leq 40$, the SOC stays at its minimum value of $20 \%$.

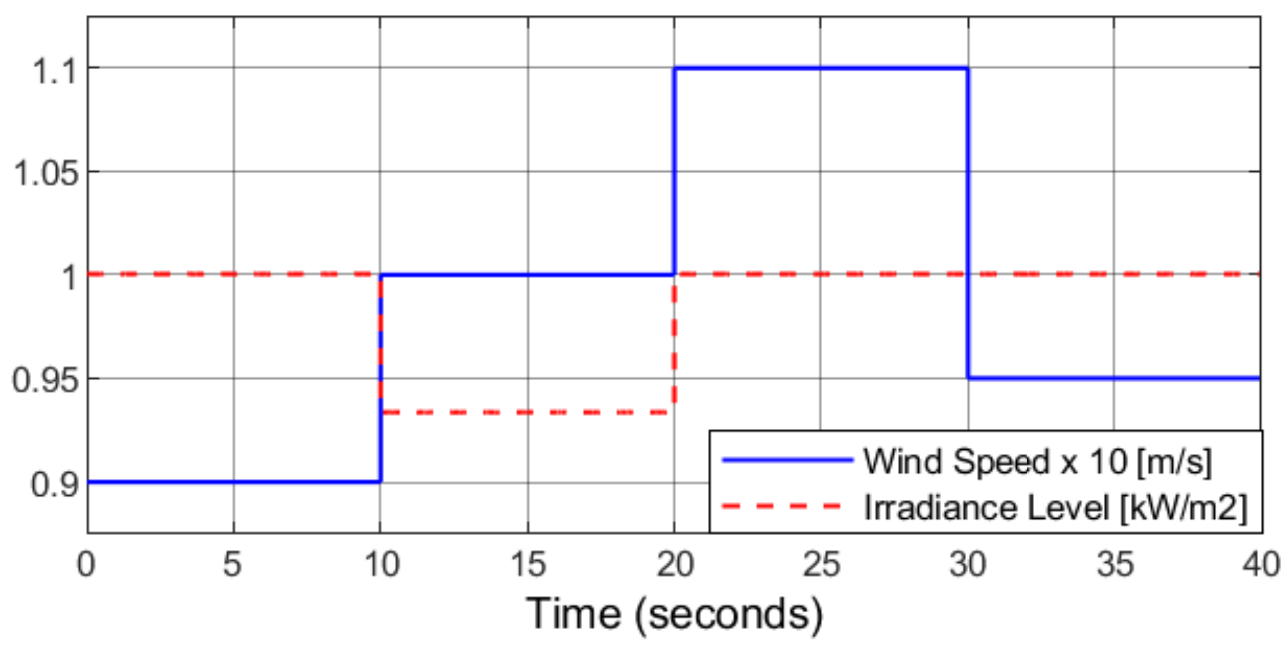

Figure 2. Irradiance level in Scenario 1 and wind speed in Scenario 2.

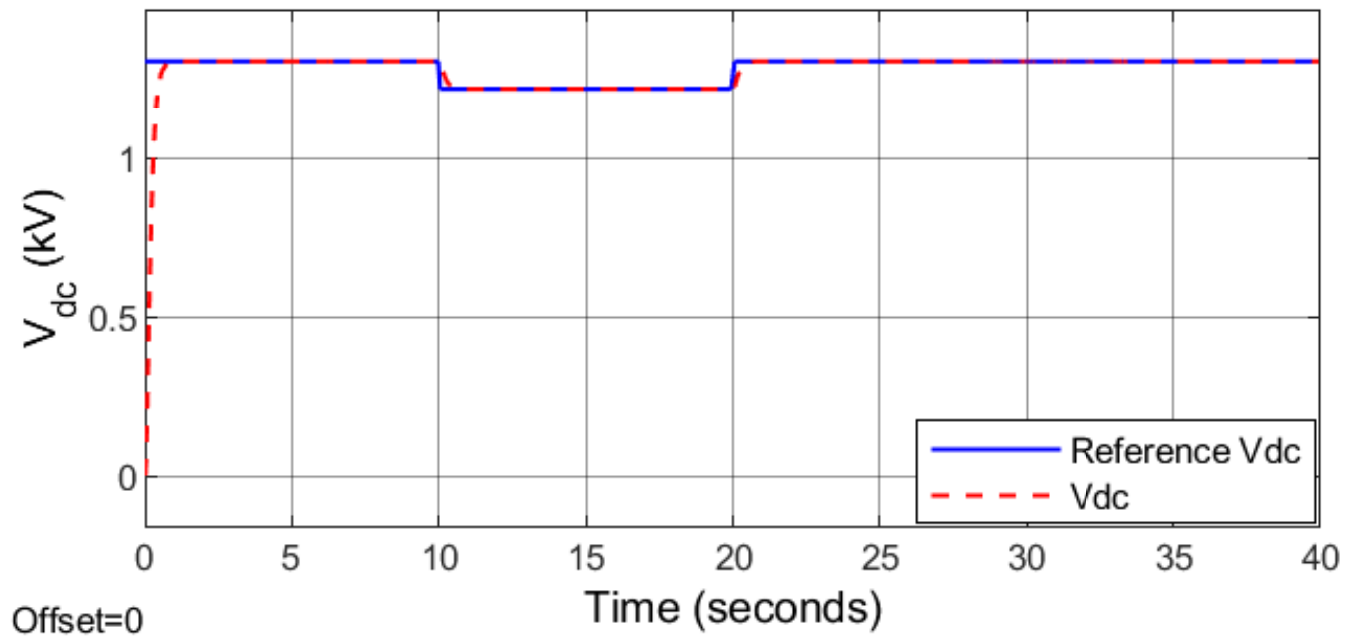

Figure 3. Scenario 1: tracking performance of the DC-link voltage. 

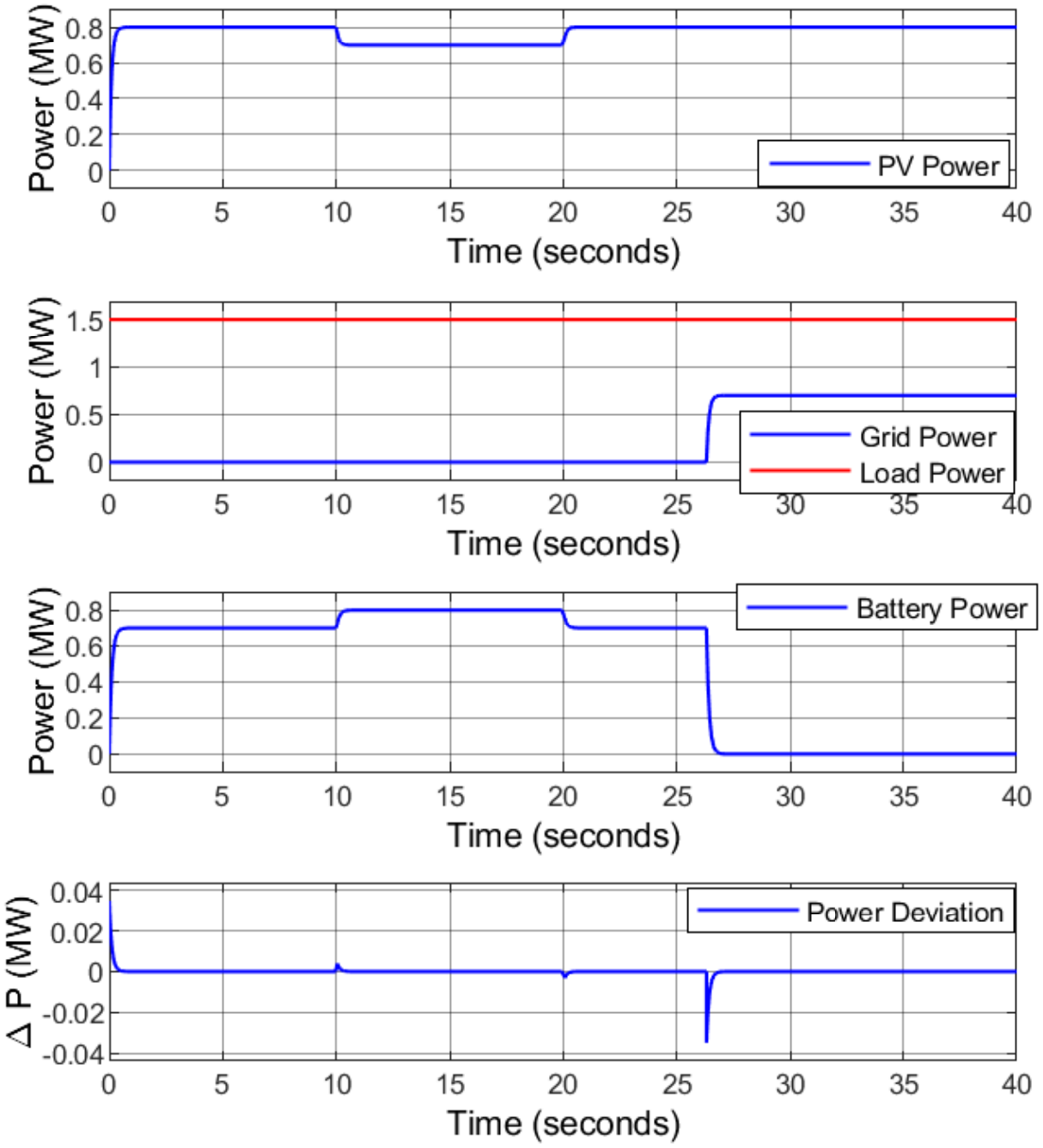

Figure 4. Scenario 1: power management of the microgrid.
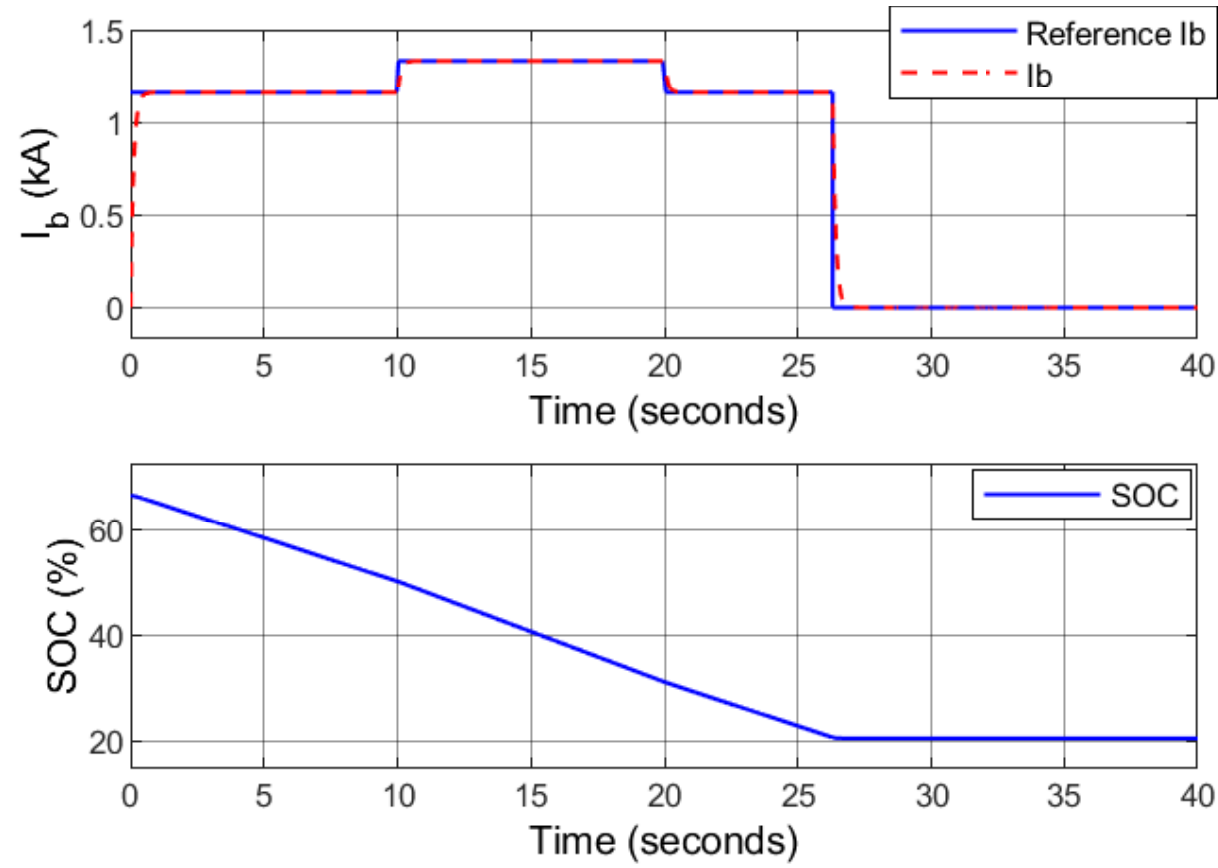

Figure 5. Scenario 1: tracking performance of the battery current and the corresponding SOC. 


\subsection{Scenario 2: Power Generation from Wind Only}

Under Scenario 2, the irradiance level is very small at night, and thus, the PV generates negligible power. Therefore, wind is the only renewable source supplying power to the constant load. As depicted in Figure 2, the wind speed rises from $9 \mathrm{~m} / \mathrm{s}$, to $10 \mathrm{~m} / \mathrm{s}, 11 \mathrm{~m} / \mathrm{s}$, and then decreases to $9.5 \mathrm{~m} / \mathrm{s}$ at $t=10 \mathrm{~s}, 20 \mathrm{~s}$, and $30 \mathrm{~s}$, respectively. Figure 6 shows how the speed of the PMSG rotor varies as the wind speed varies. Despite the variation of the wind power, the DC-link voltage is regulated to its nominal value as shown in Figure 7. From Figure 8, it can be seen that the BES is able to compensate the power deficit in the system. The utility grid is neither absorbing nor sending power to the load since the battery is operating within its allowable range. Furthermore, the power deviation $\Delta P$ remains zero. The evolution of the battery current and SOC are presented in Figure 9.

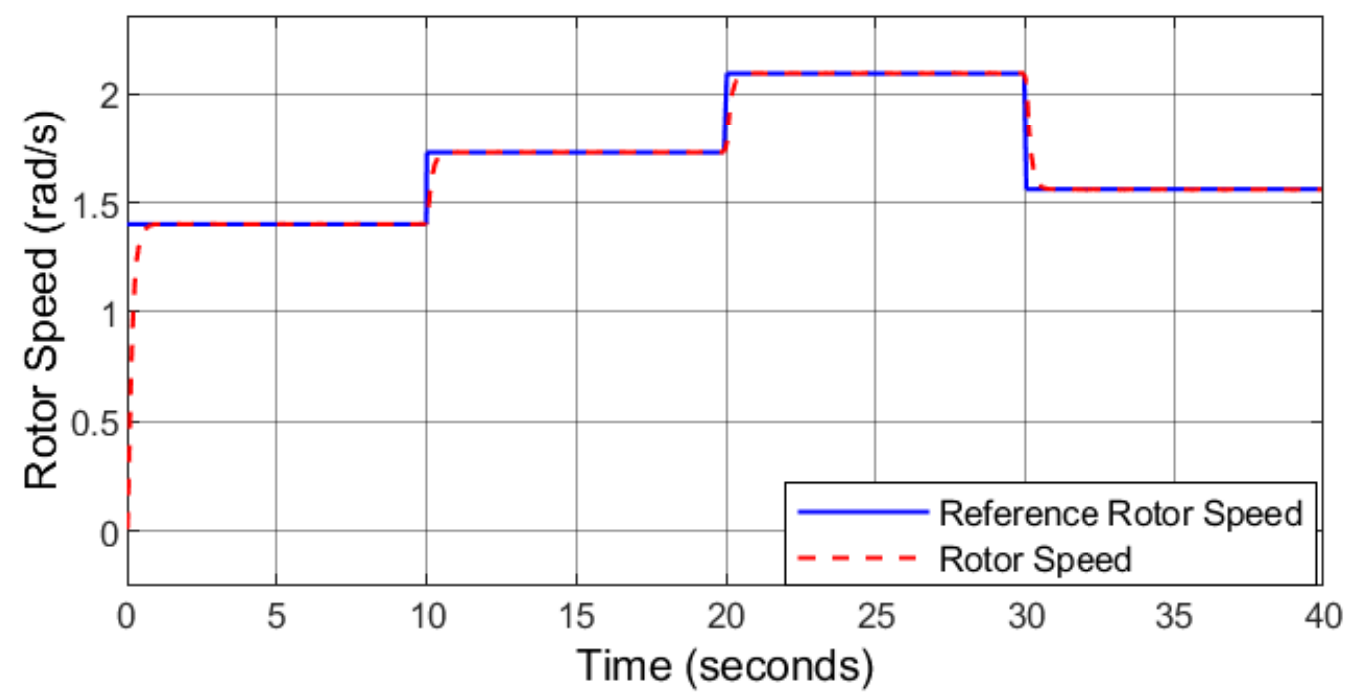

Figure 6. Scenario 2: tracking performance of the rotor speed.

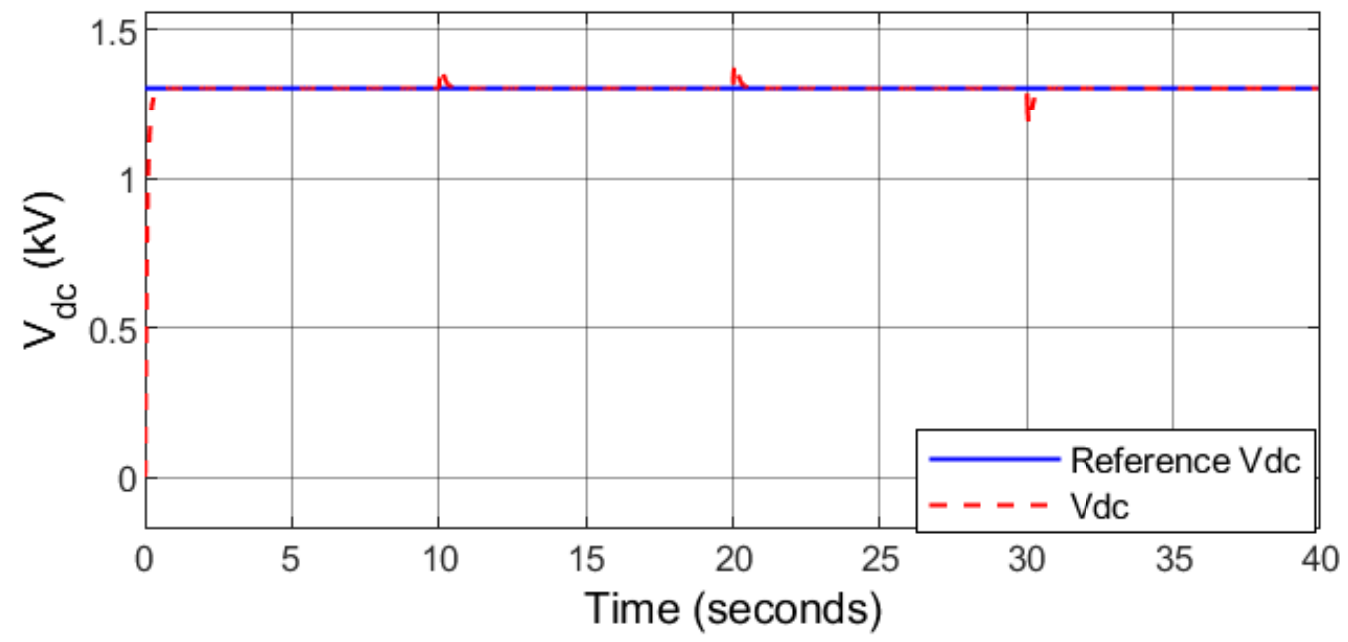

Figure 7. Scenario 2: tracking performance of the DC-link voltage. 

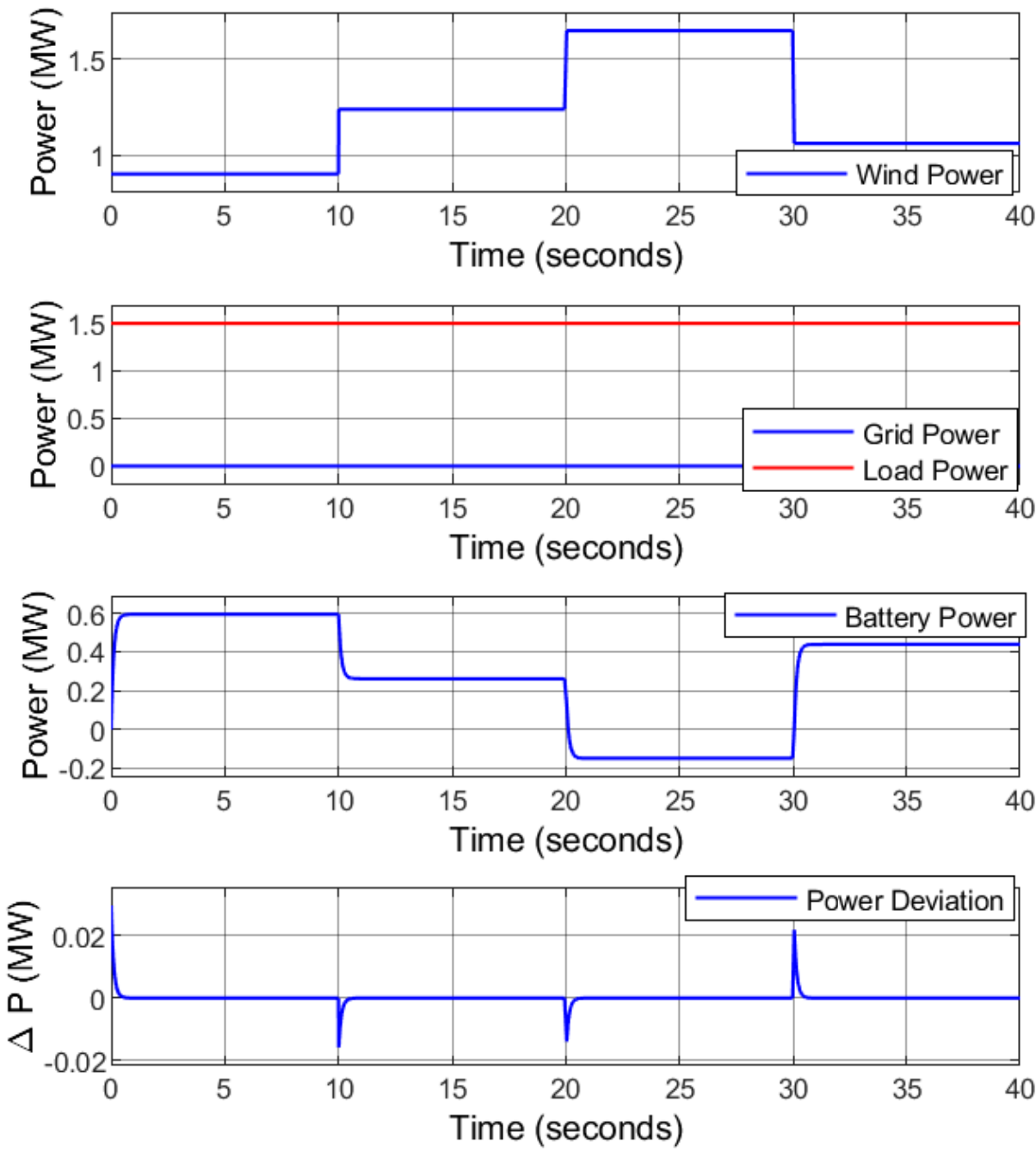

Figure 8. Scenario 2: power management of the microgrid.
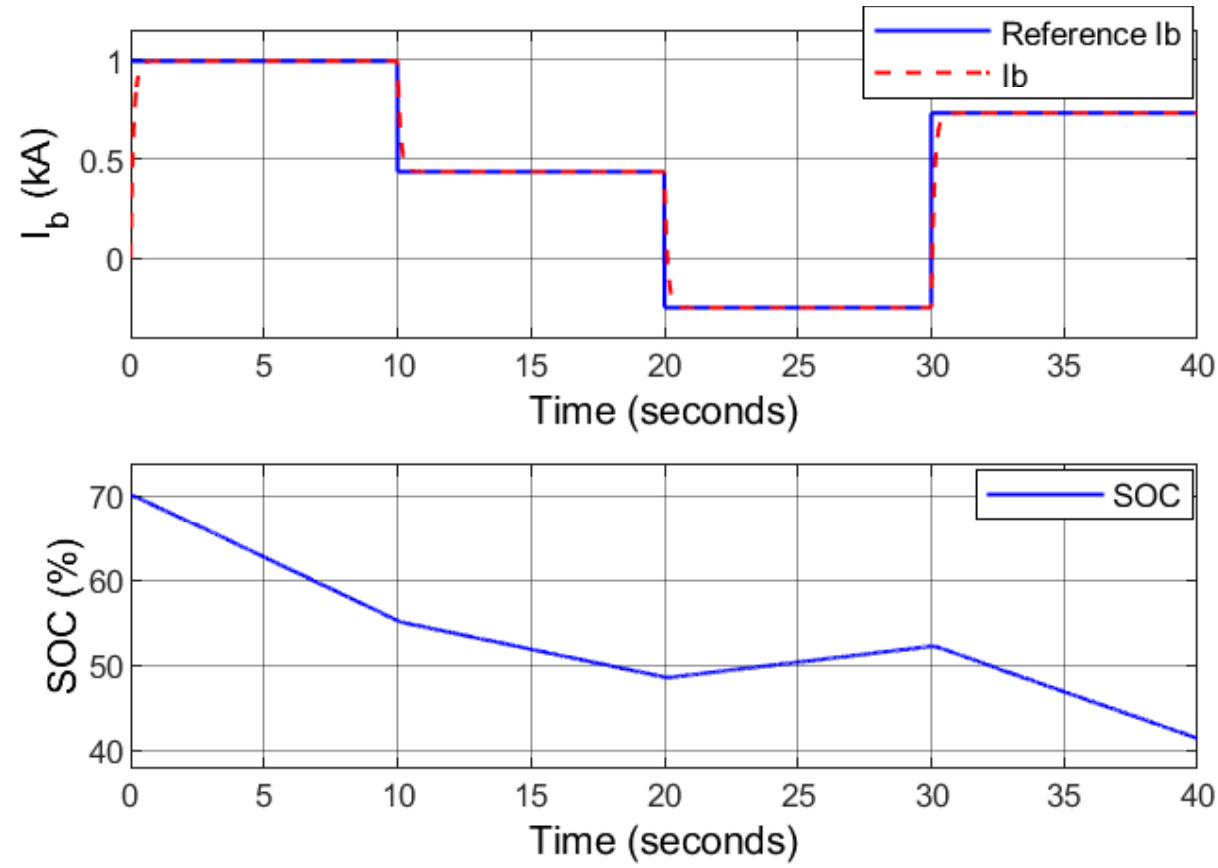

Figure 9. Scenario 2: tracking performance of the battery current and the corresponding SOC. 


\subsection{Scenario 3: Power Generation from Both Wind and PV}

Under Scenario 3, the complementary property of solar and wind power sources was investigated. As shown in Figure 10, when the solar irradiance level is still high, the wind speed is above the cut-off speed. From $t=5 \mathrm{~s}$, the solar irradiance starts decreasing while the wind speed starts increasing at $t=10 \mathrm{~s}$. Since $V_{p v}^{M P P T}$ is not below the minimum allowable DC-link voltage, the DC-link voltage tracking $V_{p v}^{M P P T}$ is shown in Figure 11. Figure 12 shows that the rotor speed increases as the wind speed increases in Figure 10. From Figure 13, it can bee seen that the load increases from $1 \mathrm{MW}$ to $1.5 \mathrm{MW}$ at $t=20 \mathrm{~s}$. When both the PV and wind power generators are operating, they are able to meet the load demand. On the other hand, the BES stores the excess power. When the battery SOC reaches its maximum value at $t=32.3 \mathrm{~s}$, the battery stops charging and the utility grid absorbs the excess power. The power deviation $\Delta P$ converges to zero. The responses of the battery current and SOC are depicted in Figure 14.

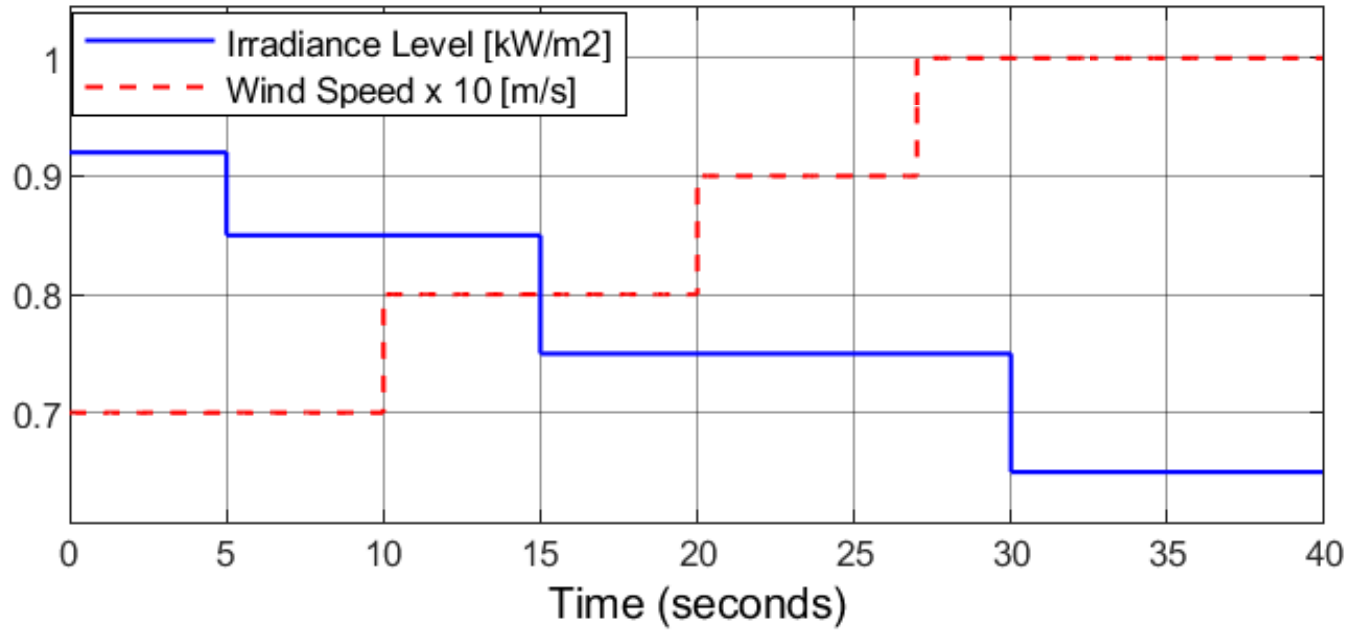

Figure 10. Scenario 3: irradiance level and wind speed.

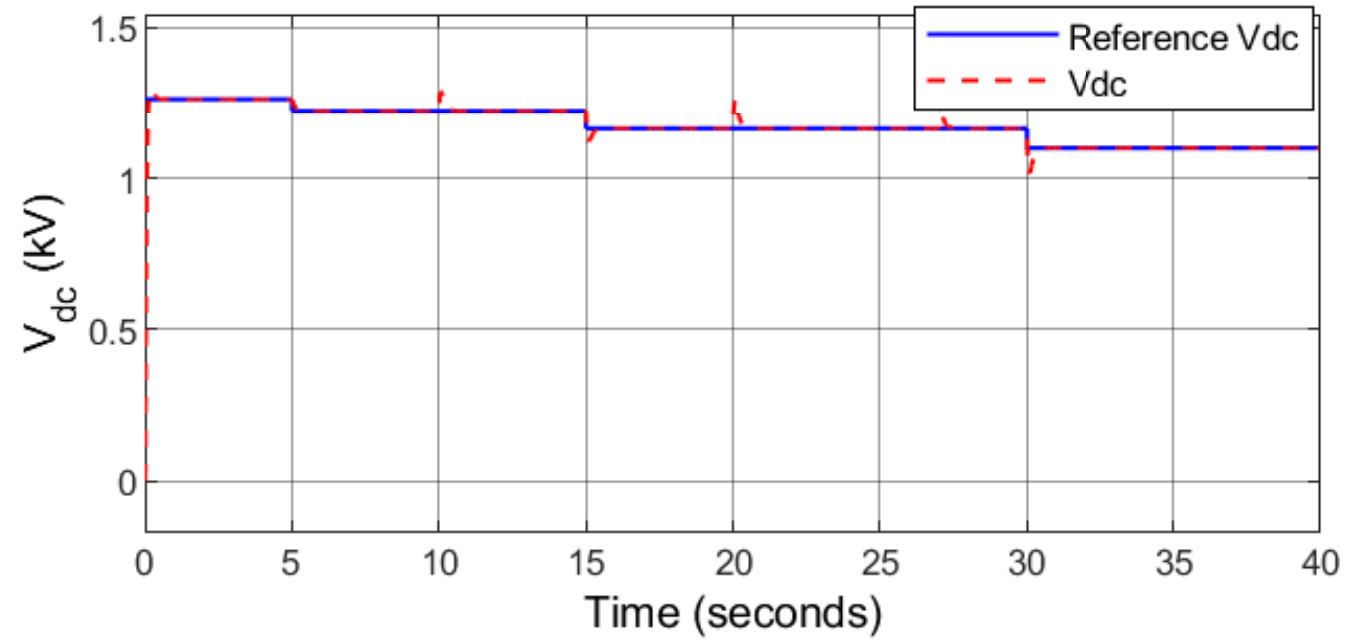

Figure 11. Scenario 3: tracking performance of the DC-link voltage. 


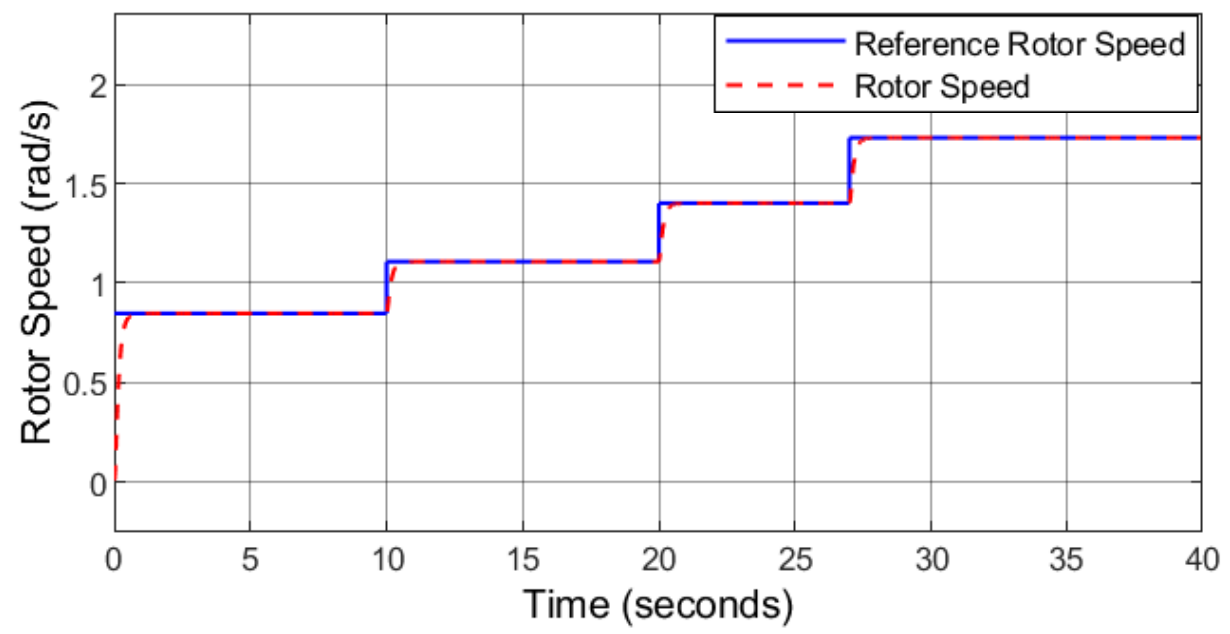

Figure 12. Scenario 3: tracking performance of the rotor speed.
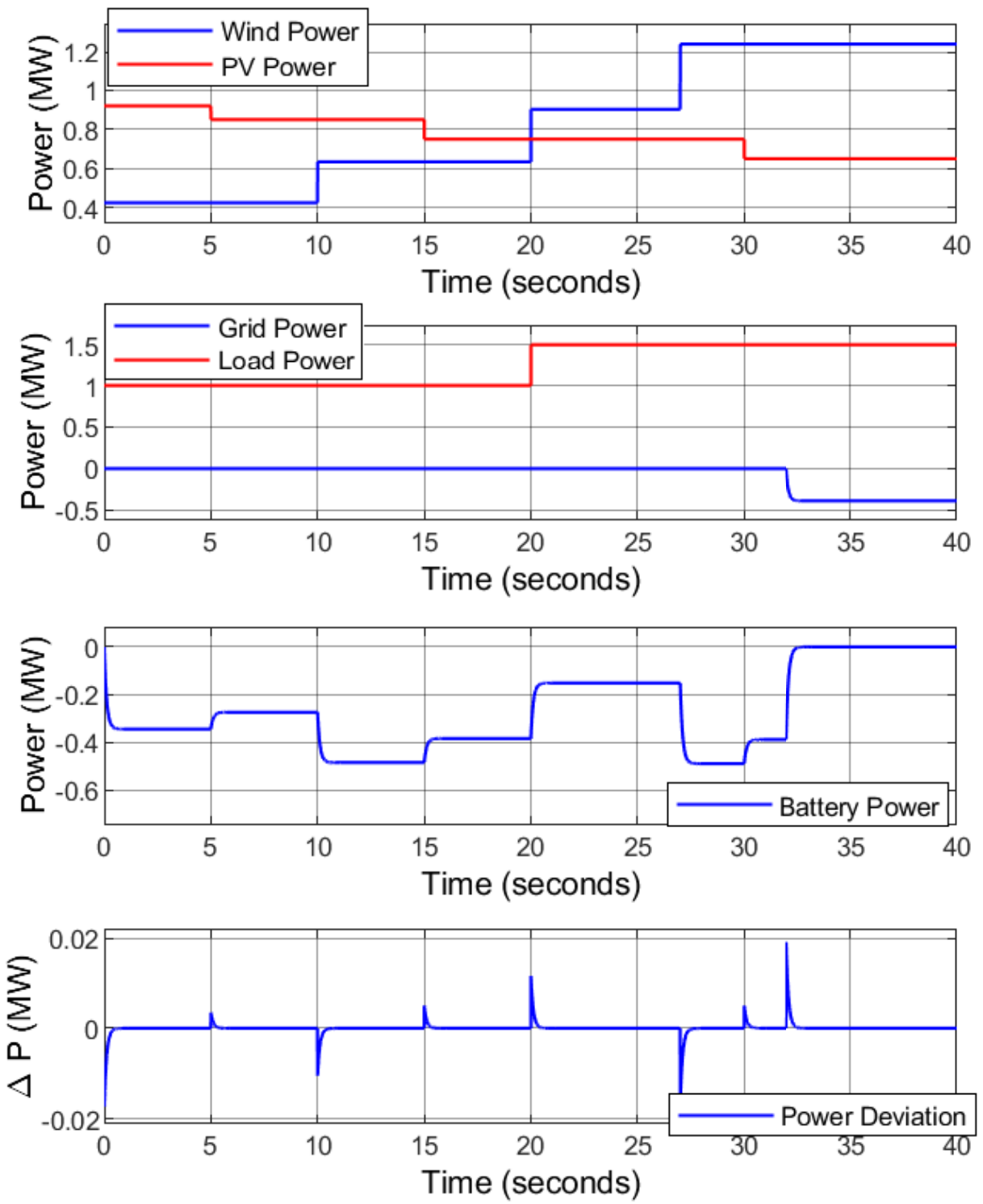

Figure 13. Scenario 3: power management of the microgrid. 

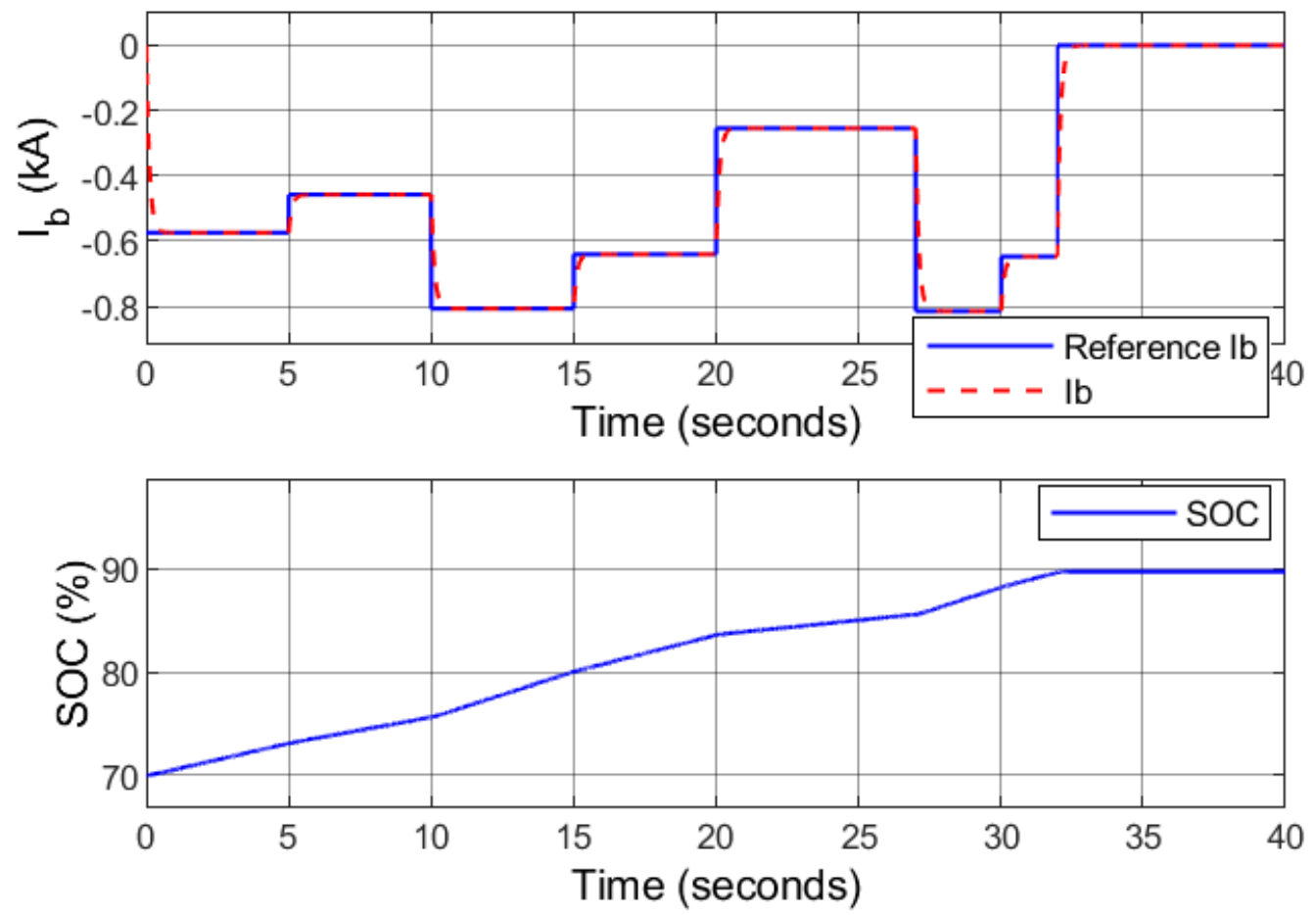

Figure 14. Scenario 3: tracking performance of the battery current and the corresponding SOC.

\subsection{Scenario 4: Comparison with the PI Controller}

Under Scenario 4, the superiority of the proposed GSMCFO was evaluated in comparison with a linear PI controller utilized in [36]. A parametric uncertainty of $\pm 50 \%$ and constant disturbances were incorporated into the hybrid microgrid operating in the conditions of Scenario 4. As depicted in Figure 15, the PI gave unsatisfactory transient and steady-state performances due to the lumped disturbances in the system and sudden load and power generation variations. Moreover, PI controller struggled to maintain $\Delta P=0$ due to the lack of robustness and fast convergence. From the same figure, it can be observed that the proposed GSMCFO has excellent transient and steady-state performances. Moreover, it is able to keep the power balance of the system despite the lumped disturbances in the system and sudden load and power generation variations. The settling time and the overshoot comparison between the proposed GSMCFO and PI controller are presented in Tables 4 and 5, respectively. From these tables, it can be deduced that the PI controller cannot be accepted in a real implementation if a good tracking performance is required in the presence of parametric uncertainties and external disturbances.

Table 4. Settling time comparison between the PI controller and the GSMCFO.

\begin{tabular}{ccccc}
\hline & $\omega_{\boldsymbol{r}}$ & $\boldsymbol{V}_{\boldsymbol{d c}}$ & $\boldsymbol{I}_{\boldsymbol{b}}$ & $\boldsymbol{\Delta P}$ \\
\hline PI & 3.6 & 7.3 & 3.6 & 4.5 \\
GSMCFO & 0.7 & 0.2 & 0.8 & 0.8 \\
\hline
\end{tabular}

Table 5. Overshoot comparison between the PI controller and GSMCFO.

\begin{tabular}{ccccc}
\hline & $\omega_{r}$ & $V_{d c}$ & $\boldsymbol{I}_{b}$ & $\boldsymbol{\Delta}$ \\
\hline PI & $51.2 .0 \%$ & $32.7 \%$ & $15.3 \%$ & $12.8 \%$ \\
GSMCFO & $0.0 \%$ & $0.0 \%$ & $0.0 \%$ & $0.0 \%$ \\
\hline
\end{tabular}



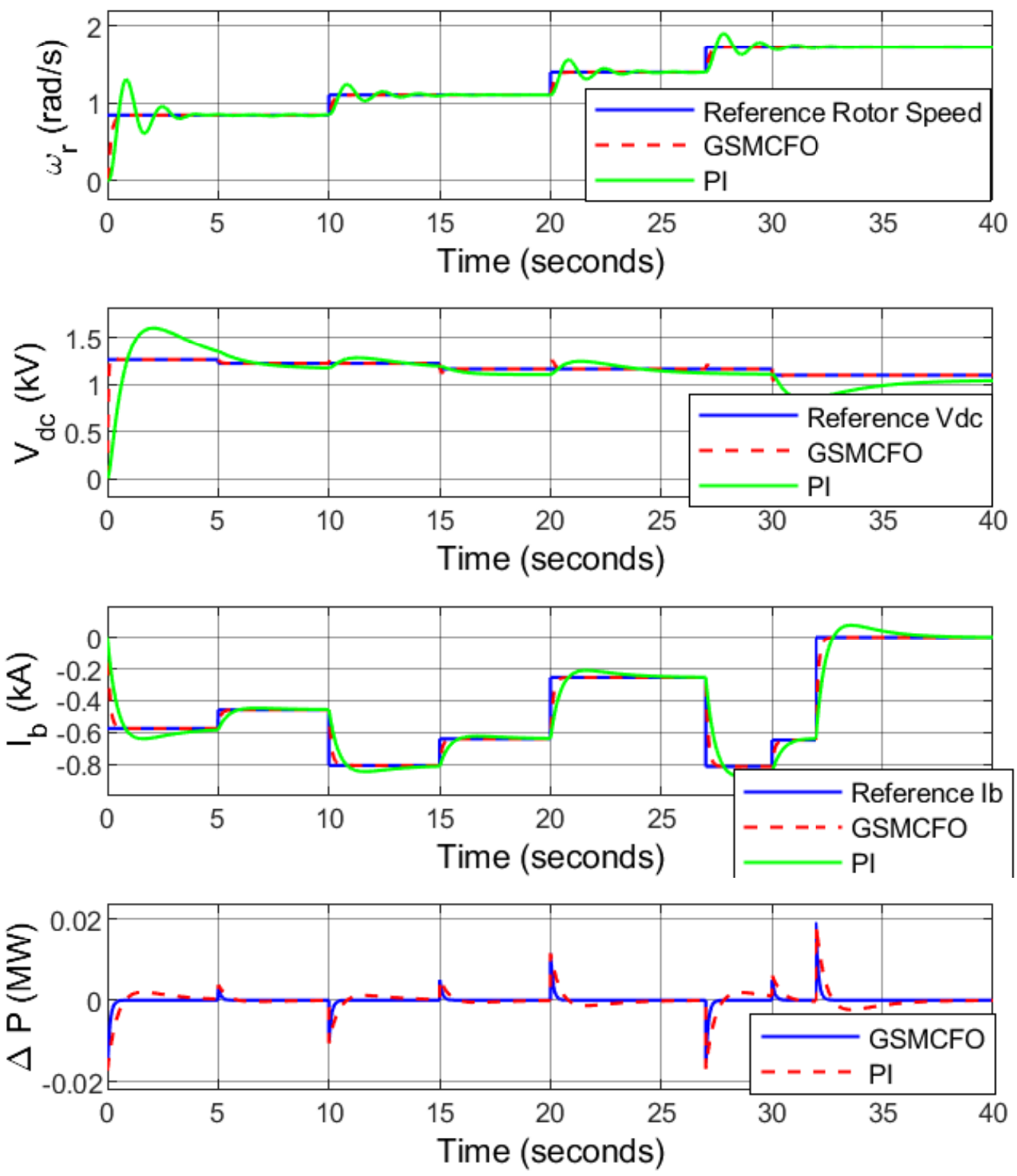

Figure 15. Scenario 4: performance comparison of the proposed GSMCFO with the PI controller.

\section{Conclusions}

This article presented a GSMCFO for a hybrid microgrid comprising a wind/PV system integrated with a BES. An efficient and cost-effective hybrid microgrid configuration was achieved by linking the PV system directly with the DC-link without the interfacing boost converter. This reduces the number of electronic converters and thus lowers the cost of the system. To obtain the proper operation of the hybrid microgrid, a GSMCFO was designed and a DE technique was used to optimize its performances. Four scenarios were provided to demonstrate the performance of the GSMCFO under various power generation and load conditions. In each of these scenarios, the proposed GSMCFO achieved the following objectives: (a) excellent transient and steady-state performances, (b) global stability of the hybrid microgrid subjected to parametric uncertainties, variation of renewable power sources, and load, (c) regulation of DC-link voltage irrespective of the operating conditions, (d) extracting maximum power from both the wind and PV systems by the RSC and GSC, respectively, (e) active power transfer to the grid, and (f) maintaining the power balance of the hybrid microgrid by effective charging/discharging of the BES. Due to the robustness and fast convergence of the GSMCFO, the overshoots in $\omega_{r}, V_{d c}, I_{b}$, and $\Delta P$ were $0.0 \%$, and 
they settled at $0.7 \mathrm{~s}, 0.2 \mathrm{~s}, 0.8 \mathrm{~s}$, and $0.8 \mathrm{~s}$, respectively. The proposed GSMCFO was also proven to outperform the PI controller in terms of overshoot and settling time. Therefore, the proposed GSMCFO can improve the power balance of the hybrid microgrid.

Author Contributions: Conceptualization, M.M.; methodology, M.M.; software, M.M.; validation, M.M. and M.K.; formal analysis, M.M. and M.K.; investigation, M.M.; resources, M.M. and M.K.; data curation, M.M.; writing-original draft preparation, M.M.; writing-review and editing, M.M. and M.K.; visualization, M.M. and M.K.; supervision, M.K.; project administration, M.M. and M.K.; funding acquisition, M.M. All authors have read and agreed to the published version of the manuscript.

Funding: This work was supported by the Center of Renewable Energy and Power Systems at King Fahd University of Petroleum \& Minerals under Project No. INRE2106.

Institutional Review Board Statement: Not applicable.

Informed Consent Statement: Not applicable.

Acknowledgments: The authors would like to acknowledge the support provided by the Center of Renewable Energy and Power Systems at King Fahd University of Petroleum \& Minerals under Project No. INRE2106 and King Abdullah City for Atomic and Renewable Energy (K.A.CARE).

Conflicts of Interest: The authors declare no conflict of interest.

\section{Abbreviations}

MPPT maximum power point tracking

HRES hybrid renewable energy sources

PCC point of common coupling

PV photovoltaic

GSC grid-side converter

RSC rotor-side converter

DC direct current

DFIG doubly-fed induction generator

PMSG permanent magnet synchronous generator

GSMCFO global sliding-mode control with fractional-order terms

\section{Parameters}

$L_{d} \quad d$-axis self-inductance

$L_{q} \quad q$-axis self-inductance

$R \quad$ radius of the wind turbine

$\rho \quad$ density of air

$J \quad$ inertia of the mechanical shaft

$T_{m} \quad$ mechanical torque

$T_{e} \quad$ electrical torque

$\rho \quad$ density of air

$\Lambda_{r} \quad$ rotor flux

$R_{S} \quad$ stator resistance

$L_{b} \quad$ battery inductance

$V_{b} \quad$ battery voltage

$\eta_{b} \quad$ battery efficiency

$Q_{b} \quad$ battery capacity

$S O C^{\text {min }} \quad$ lower limit of the SOC

$S O C^{\max } \quad$ upper limit of the SOC

$\rho \quad$ density of air

$N_{s} \quad$ number of series-connected modules

$N_{p} \quad$ number of parallel-connected modules

$R_{\text {se }} \quad$ equivalent series resistors

$k_{B} \quad$ Boltzmann constant

$q \quad$ electron charge

A p-n junction factor 
T

$R_{s h}$

$\omega_{g}$

$L_{f}$

$R_{f}$

$B$

$q$

A

$B$

$L_{f}$

D

$C_{d c}$

$V_{\text {dio }}$

\section{Variables}

$I_{d s}$

$I_{q s}$

$I_{d}$

$I_{q}$

$I_{b}$

$I_{p h}$

$I_{s}$

$\omega_{r}$

$I_{p v}$
$V_{d}$

$V_{q}$

$V_{d s}$

$V_{q s}$

$u_{d}$

$U_{q}$

$I_{b}$

$V_{b}$

$V_{d c}$

$I_{g d c}$

SOC

$I_{p h}$

$I_{S}$

$I_{p v}$

$V_{p v}$

$V_{w}$

$C_{p}$

$\beta$

$\lambda$

$\lambda_{\text {opt }}$

$V_{d c}$

$V_{p v}$

$P_{b}$

$P_{p v}$

$P_{m}$ ambient temperature

equivalent shunt resistors

electrical angular speed

grid-side filter inductance

grid-side filter resistance

Boltzmann constant

electron charge

$\mathrm{p}-\mathrm{n}$ junction factor

Boltzmann constant

grid-side filter inductance

duty cycle

DC-link capacitance

diode voltage

\section{$d$-axis stator current}

$q$ axis stator current

GSC $d$-axis output AC current

GSC $q$ axis output AC current

battery current

photo-generated currents

saturated currents

angular speed of the wind turbine

PV output current

GSC $d$-axis output voltage

GSC $q$-axis output voltage

$d$-axis stator voltage

$q$ axis stator voltage

$d$-axis PCC voltage

$q$-axis PCC voltage

battery current

battery voltage

DC-link voltage

GSC DC current

state-of-charge

photo-generated currents

saturated currents

PV output current

PV output voltage

wind speed

power coefficient

pitch angle

tip speed ratio

optimal tip speed ratio

DC-link voltage

PV output voltage

battery power

solar power

wind power

\section{References}

1. Hannan, M.; Lipu, M.H.; Ker, P.J.; Begum, R.; Agelidis, V.G.; Blaabjerg, F. Power electronics contribution to renewable energy conversion addressing emission reduction: Applications, issues, and recommendations. Appl. Energy 2019, 251, 113404. [CrossRef]

2. Maaruf, M.; Elfrik, S.; Mahmoud, M.S. Integral Sliding Mode Control With Power Exponential Reaching Law for DFIG. In Proceedings of the 2020 17th International Multi-Conference on Systems, Signals Devices (SSD), Sfax, Tunisia, 20-23 July 2020; pp. 1122-1127. [CrossRef] 
3. Khalid, M. Wind Power Economic Dispatch-Impact of Radial Basis Functional Networks and Battery Energy Storage. IEEE Access 2019, 7, 36819-36832. [CrossRef]

4. Fahad, A.; Mohamed, A.A.; Muhammad, K. Optimal Coordinated Planning of Energy Storage and Tie-Lines to Boost Flexibility with High Wind Power Integration. Sustainability 2021, 13, 2526.

5. Jamal, S.; Tan, N.M.L.; Pasupuleti, J. A Review of Energy Management and Power Management Systems for Microgrid and Nanogrid Applications. Sustainability 2021, 13, 10331. [CrossRef]

6. Hansen, K.; Mathiesen, B.V.; Skov, I. Full energy system transition towards 100 renewable energy in Germany in 2050. Renew. Sustain. Energy Rev. 2019, 102, 1-13. [CrossRef]

7. Alayi, R.; Zishan, F.; Seyednouri, S.R.; Kumar, R.; Ahmadi, M.H.; Sharifpur, M. Optimal Load Frequency Control of Island Microgrids via a PID Controller in the Presence of Wind Turbine and PV. Sustainability 2021, 13, 10728. [CrossRef]

8. Akram, U.; Khalid, M.; Shafiq, S. An Innovative Hybrid Wind-Solar and Battery-Supercapacitor Microgrid System-Development and Optimization. IEEE Access 2017, 5, 25897-25912. [CrossRef]

9. Maaruf, M.; Shafiullah, M.; Al-Awami, A.T.; Al-Ismail, F.S. Adaptive Nonsingular Fast Terminal Sliding Mode Control for Maximum Power Point Tracking of a WECS-PMSG. Sustainability 2021, 13, 13427. [CrossRef]

10. Priyadarshi, N.; Ramachandaramurthy, V.K.; Padmanaban, S.; Azam, F. An Ant Colony Optimized MPPT for Standalone Hybrid PV-Wind Power System with Single Cuk Converter. Energies 2019, 12, 167. [CrossRef]

11. Priyadarshi, N.; Padmanaban, S.; Bhaskar, M.S.; Blaabjerg, F.; Holm-Nielsen, J.B. An improved hybrid PV-wind power system with MPPT for water pumping applications. Int. Trans. Electr. Energy Syst. 2020, 30, e12210. [CrossRef]

12. Hrovatin, D.; Žemva, A. Exploiting Solar Energy during an Aerial Mapping Mission on a Lightweight UAV. Electronics 2021, 10, 2876. [CrossRef]

13. Youssef, A.R.; Ali, A.I.; Saeed, M.S.; Mohamed, E.E. Advanced multi-sector P\&O maximum power point tracking technique for wind energy conversion system. Int. J. Electr. Power Energy Syst. 2019, 107, 89-97.

14. Gupta, T.N.; Murshid, S.; Singh, B. Power quality improvement of single phase weak grid interfaced hybrid solar PV and wind system using double fundamental signal extracter-based control. IET Gener. Transm. Distrib. 2019, 13, 3988-3998. [CrossRef]

15. Nguyen, D.; Fujita, G. Dynamic response evaluation of sensorless MPPT method for hybrid PV-DFIG wind turbine system. J. Int. Counc. Electr. Eng. 2016, 6, 49-56. [CrossRef]

16. Neeraj, P. Fuzzy SVPWM-based inverter control realisation of grid integrated photovoltaic-wind system with fuzzy particle swarm optimisation maximum power point tracking algorithm for a grid-connected PV/wind power generation system: Hardware implementation. IET Electr. Power Appl. 2018, 12, 962-971.

17. Rezvani, A.; Esmaeily, A.; Etaati, H.; Mohammadinodoushan, M. Intelligent hybrid power generation system using new hybridfuzzy-neural for photovoltaic system and RBFNSM for windturbine in the grid connected mode. Front. Energy 2019, 6, 131-148. [CrossRef]

18. Morshed, M.J.; Fekih, A. A Novel Fault Ride through Scheme for Hybrid Wind/PV Power Generation Systems. IEEE Trans. Sustain. Energy 2020, 11, 2427-2436. [CrossRef]

19. Guo, Y.; Wu, Q.; Gao, H.; Chen, X.; Østergaard, J.; Xin, H. MPC-Based Coordinated Voltage Regulation for Distribution Networks With Distributed Generation and Energy Storage System. IEEE Trans. Sustain. Energy 2019, 10, 1731-1739. [CrossRef]

20. Sofia, B. Online battery state-of-charge estimation methods in micro-grid systems. J. Energy Storage 2020, $30,101518$.

21. Ahmed, A.; Hussain, A.; Muhammad, K. Minimization of Power Losses through Optimal Battery Placement in a Distributed Network with High Penetration of Photovoltaics. Energies 2020, 13, 140.

22. Venugopal, P.; Shankar, S.S.; Jebakumar, C.P.; Agarwal, R.; Alhelou, H.H.; Reka, S.S.; Golshan, M.E.H. Analysis of Optimal Machine Learning Approach for Battery Life Estimation of Li-Ion Cell. IEEE Access 2021, 9, 159616-159626. [CrossRef]

23. Hu, J.; He, H.; Wei, Z.; Li, Y. Disturbance-Immune and Aging-Robust Internal Short Circuit Diagnostic for Lithium-Ion Battery. IEEE Trans. Ind. Electron. 2022, 69, 1988-1999. [CrossRef]

24. Zhang, Y.; Xiong, R.; He, H.; Pecht, M.G. Long Short-Term Memory Recurrent Neural Network for Remaining Useful Life Prediction of Lithium-Ion Batteries. IEEE Trans. Veh. Tech. 2018, 67, 5695-5705. [CrossRef]

25. Sethia, G.; Nayak, S.K.; Majhi, S. An Approach to Estimate Lithium-Ion Battery State of Charge Based on Adaptive Lyapunov Super Twisting Observer. IEEE Trans. Circuits Syst. I Regul. Pap. 2021, 68, 1319-1329. [CrossRef]

26. Wei, Z.; Meng, S.; Xiong, B.; Ji, D.; Tseng, K.J. Enhanced online model identification and state of charge estimation for lithium-ion battery with a FBCRLS based observer. Appl. Energy 2016, 181, 332-341. [CrossRef]

27. Meng, G.; Lu, Y.; Liu, H.; Ye, Y.; Sun, Y.; Tan, W. Adaptive Droop Coefficient and SOC Equalization-Based Primary Frequency Modulation Control Strategy of Energy Storage. Electronics 2021, 10, 2645. [CrossRef]

28. Ali, A.Y.; Basit, A.; Ahmad, T.; Qamar, A.; Iqbal, J. Optimizing coordinated control of distributed energy storage system in microgrid to improve battery life. Comput. Electr. Eng. 2020, 86, 106741. [CrossRef]

29. Zhou, J.; Sun, H.; Xu, Y.; Han, R.; Yi, Z.; Wang, L.; Guerrero, J.M. Distributed Power Sharing Control for Islanded Single-/Three-Phase Microgrids With Admissible Voltage and Energy Storage Constraints. IEEE Trans. Smart Grid 2021, 12, 2760-2775. [CrossRef]

30. Ryan, D.J.; Razzaghi, R.; Torresan, H.D.; Karimi, A.; Bahrani, B. Grid-Supporting Battery Energy Storage Systems in Islanded Microgrids: A Data-Driven Control Approach. IEEE Trans. Sustain. Energy 2021, 12, 834-846. [CrossRef]

31. Miguel, M.D.; Édinson, F.M.; Rivas, T.E.; Luis, R.A.J.; Santiago, A. Coordinated Control System between Grid-VSC and a DC Microgrid with Hybrid Energy Storage System. Electronics 2021, 10, 2699. 
32. Puchalapalli, S.; Tiwari, S.K.; Singh, B.; Goel, P.K. A Microgrid Based on Wind-Driven DFIG, DG, and Solar PV Array for Optimal Fuel Consumption. IEEE Trans. Ind. Appl. 2020, 56, 4689-4699. [CrossRef]

33. Maaruf, M.; Khan, K.A.; Khalid, M. Integrated Power Management and Nonlinear-Control for Hybrid Renewable Microgrid. In Proceedings of the 2021 IEEE Green Technologies Conference (GreenTech), Denver, CO, USA, 7-9 April 2021 ; pp. 176-180.

34. Batiyah, S.; Sharma, R.; Abdelwahed, S.; Zohrabi, N. An MPC-based power management of standalone DC microgrid with energy storage. Int. J. Electr. Power Energy Syst. 2020, 120, 105949. [CrossRef]

35. Toghani Holari, Y.; Taher, S.A.; Mehrasa, M. Distributed energy storage system-based nonlinear control strategy for hybrid microgrid power management included wind/PV units in grid-connected operation. Int. Trans. Electr. Energy Syst. 2020, 30, e12237. [CrossRef]

36. Chishti, F.; Murshid, S.; Singh, B. LMMN-Based Adaptive Control for Power Quality Improvement of Grid Intertie Wind-PV System. IEEE Trans. Ind. Inform. 2019, 15, 4900-4912. [CrossRef]

37. Najafi-Shad, S.; Barakati, S.M.; Yazdani, A. An effective hybrid wind-photovoltaic system including battery energy storage with reducing control loops and omitting PV converter. J. Energy Storage 2020, 27, 101088. [CrossRef]

38. Radwan, A.A.A.; Mohamed, Y.A.I. Grid-Connected Wind-Solar Cogeneration Using Back-to-Back Voltage-Source Converters. IEEE Trans. Sustain. Energy 2020, 11, 315-325. [CrossRef]

39. Wang, J.; Shao, C.; Chen, Y.Q. Fractional order sliding mode control via disturbance observer for a class of fractional order systems with mismatched disturbance. Mechatronics 2018, 53, 8-19. [CrossRef]

40. Guo, Y.; Ma, B.L. Global sliding mode with fractional operators and application to control robot manipulators. Int. J. Control 2019, 92, 1497-1510. [CrossRef]

41. Xie, Y.; Zhang, X.; Meng, W.; Zheng, S.; Jiang, L.; Meng, J.; Wang, S. Coupled fractional-order sliding mode control and obstacle avoidance of a four-wheeled steerable mobile robot. ISA Trans. 2021, 108, 282-294. [CrossRef]

42. Housseini, B.; Okou, A.F.; Beguenane, R. Robust Nonlinear Controller Design for On-Grid/Off-Grid Wind Energy Battery-Storage System. IEEE Trans. Smart Grid 2018, 9, 5588-5598. [CrossRef]

43. Chatrenour, N.; Razmi, H.; Doagou-Mojarrad, H. Improved double integral sliding mode MPPT controller based parameter estimation for a stand-alone photovoltaic system. Energy Convers. Manag. 2017, 139, 97-109. [CrossRef]

44. Prince, M.K.K.; Arif, M.T.; Gargoom, A.; Oo, A.M.T.; Haque, M.E. Modeling, Parameter Measurement, and Control of PMSG-Based Grid-Connected Wind Energy Conversion System. J. Mod. Power Syst. Clean Energy 2021, 9, 1-12. [CrossRef] 